\title{
Electricity Shortages and Firm Productivity: Evidence from China's Industrial Firms
}

\author{
Karen Fisher-Vanden, Erin T. Mansur, and Qiong (Juliana) Wang*
}

January 10, 2015

Unreliable inputs to production, particularly those that are difficult to store, can significantly limit firms' productivity, leading them to react in a number of ways. This paper uses a panel of 23,000 energy-intensive, Chinese firms from 1999 to 2004 to examine how firms responded to severe power shortages in the early 2000s. Our results suggest that, in response to electricity scarcity, Chinese firms re-optimize among inputs to production by substituting materials for energy (both electric and non-electric sources) - a shift from "make" to "buy" of intermediate inputs to production. While outsourcing can be costly, Chinese firms were able to avoid substantial productivity losses by doing so. As a result of the increase in electricity scarcity from 1999 onward, we find that unit production costs increased by eight percent.

JEL Codes: D24, Q4, P2, L9

Key Words: electricity, blackouts, productivity, China, outsourcing

\footnotetext{
*Fisher-Vanden: Dept of Agric. Econ. and Rural Soc., Pennsylvania State University 112-E Armsby Bldg, University Park, PA 16802, fishervanden@psu.edu; Mansur: Dartmouth College and NBER. Department of Economics, 6106 Rockefeller Hall, Hanover, NH 03755, erin.mansur@dartmouth.edu; Wang: Environmental Studies Program, University of Southern California, 3502 Trousdale Parkway, SOS B15, MC 0036, Los Angeles, CA 90089, juliana.wang @usc.edu. This research was supported by the U.S. Department of Energy's Biological and Environmental Research Program (contract \DE-FG02-04ER63930), and the National Science Foundation (project/grant \#450823). We wish to thank Taryn Dinkelman, Eric Edmonds, Jun Ishii, Josh Linn, Nancy Rose, Connie Shang, and seminar participants at the UC Energy Institute, Harvard University, the ASSA meetings, and NBER for helpful comments.
} 


\section{Introduction}

Resource availability and input factor reliability are important for firm productivity, and are especially problematic in developing countries like China. For some resources, like water, storage devices can be used to manage unreliable services (Baisa et al. 2010). However, unreliable delivery of electricity requires that firms respond in other ways, as power is prohibitively expensive to store.

Over the past few decades, investment in the Chinese power sector has experienced a boom-bust cycle. Beginning in 1985, the central government transferred ownership of power plants to local governments and firms. At first, this "privatization" provided suppliers with an incentive to invest in new power capacity. In fact, the rapid increase in new power plant construction during the 1990s lead to a glut of capacity (IEA 2006). In response, the national government imposed a building moratorium on new power plants in 1999. As a result, within just a few years, this excess supply had disappeared as demand quickly caught up with supply.

From 2000 to 2007, demand for electric power in China grew 41\% (EIA 2009). Most of this growth can be attributed to growth in the manufacturing sector, particularly in construction-related products like steel and cement. By 2006, the manufacturing sector comprised $74 \%$ of total electricity consumption (NBS 2007). In addition, while a smaller overall share, household demand had been growing about $12 \%$ per year during this time period. This was exacerbated by the fact that retail electricity remained under price-cap regulation with limited price response to shortages. Finally, residential and commercial electricity consumers were given priority over other customers, resulting in even less electricity available for use by industrial sectors. Power availability and reliability were 
further aggravated during the early 2000s by unusually hot summers and cold winters, extreme weather events such as snow storms in the mid-South, and a shortage in coal supply (Lin et al. 2005, Wang 2007). As a result, 26 of the 30 Chinese provinces experienced blackouts associated with resource scarcity issues from 2002 to 2004 (Chen and Jia 2006).

While the early 2000's were historic in terms of the number of blackouts, electricity shortages continue to remain a major concern for China. As recently as the summer of 2011, China faced substantial power shortages. ${ }^{1}$ The severity of these electricity shortages dwarfs recent experiences in the United States. In 2004, China's Eastern electricity grid (an area including Shanghai) alone curtailed over 13,000,000 MWh, accounting for over two percent of annual consumption. In comparison, the rolling blackouts of California's power crisis in 2000-2001 curtailed less than one 1000th of that amount. $^{2}$

In this paper, we apply econometric techniques to an unbalanced panel of firmlevel data comprising approximately 23,000 of the most energy-consuming firms in 11 industries in China from 1999 to 2004 to examine firm responses to the threat of electricity shortages. ${ }^{3,4}$ In particular, we estimate a flexible cost function and test whether

\footnotetext{
${ }^{1}$ Shanghai Securities News (http://english.cnstock.com/enghome/homeheadline/201105/1307904.htm (Accessed December 19, 2011)).

${ }^{2}$ In 2004, Eastern China used 2.5 times as much electricity as California. Curtailment data are from China's Eastern Grid Company (personal communication) and the California Public Utilities Commission (http://docs.cpuc.ca.gov/word\_pdf/misc/generation+report.pdf accessed June 20, 2008), respectively. Below we discuss how China's electricity sector is made up of several transmission grids.

${ }^{3}$ The data are by enterprise, which we refer to as a "firm" throughout this paper. In the data, an enterprise refers to a business organization but is not aggregated to the parent-company level.

${ }^{4}$ As discussed in Section 4 below, we prefer to use a measure of electricity scarcity that captures the threat of scarcity, since firms will make investment decisions based on the potential threat of scarcity whether or not that particular firm has experienced a blackout. Thus, we use the ratio of thermal generation to capacity as our measure of threat.
} 
input factor shares or overall productivity change with shocks to an electricity grid's degree of scarcity. We use weather data to instrument for potential measurement error and endogeneity concerns.

Our results suggest that Chinese firms re-optimize in response to electricity scarcity. Primarily, they shift from purchases of energy inputs (from both electric and non-electric, primary energy sources) into material inputs. This is consistent with the hypothesis of outsourcing: firms in regions where electric power became scarcer shift from "make" to "buy" of intermediate goods for production. Further, we do not find evidence that electricity scarcity led to an increase in self generation. This is in contrast to findings from papers that study countries with long-term electricity supply issues (for example, Allcott et al. 2014 for India), although the factors behind these shortages are different.

Our results find that, across all industries, the increase in material inputs expenditures in response to electricity shortages since 1999 increased unit production costs by 13 percent. We find the largest effects in the wood products (e.g., furniture), chemicals, food, metal, and textiles industries. However, this $13 \%$ increase in unit cost due to greater spending on materials is partially offset by a $5 \%$ reduction in unit cost due to savings in the other inputs and small total factor productivity improvements.

Therefore, the net effect of these factor-biased and factor-neutral effects is an $8 \%$ increase in unit costs. Thus, while outsourcing can be costly, Chinese firms were able to avoid substantial productivity losses by doing so since it led to savings elsewhere in the production process. 
This paper proceeds as follows. In Section 2, we describe the causes of and regulatory response to China's power shortage. Section 3 provides a discussion of alternative ways that firms may respond to issues of electricity scarcity. Sections 4 and 5 describe our data and empirical model, respectively. In Section 6, we report our results. We estimate the overall productivity losses attributable to the power shortages in Section 7, and conclude in Section 8.

\section{Government Responses to Electricity Shortages}

The Chinese government utilized both demand and supply side mechanisms in response to the electricity shortages in the early 2000's. On the demand side, some dynamic pricing mechanisms were instituted to smooth the load between peak and offpeak times. For example, Jiangsu province implemented time-of-use pricing starting in 2003. However, the effectiveness of this pricing policy was limited by regulatory control on prices and the slow installation of real-time meters.

In addition, the government reduced subsidies for some industries. Since the mid1980s, the national government has subsidized purchased power for energy-intensive industries including aluminum, cement, steel, and other metal and non-metal manufacturing. The fertilizer and agriculture sectors are the most heavily subsidized industries. In Junan Province, firms in these industries paid about a quarter the rate of commercial users in 1999. Even during the crisis, these industries continued to receive extremely low rates. However, for many industries, reduced subsidies and increased rates began in 2002. 
These pricing mechanisms, however, did not sufficiently curtail demand. As a result, local governments were forced to address these shortages through either scheduled blackouts (via quota rationing), or rolling, stochastic blackouts. Planned outages and changes in production schedules were imposed to deal with the shortages. For example, in the summer of 2003, the city of Hangzhou implemented a detailed plan for rolling blackouts for industrial customers. These measures include: shifting firms with noncontinuous production to alternative working days (e.g., three-day per week production schedules); controlling and cutting off electricity consumption at continuous production firms during peak hours; moving energy-intensive production to night hours; limiting power supply to key firms and projects; and lowering electricity consumption of commercial users. The cities of Nanjing, Shanghai, and Shantou also released similar plans during that period.

The Chinese government also implemented supply-side policies to expand generation. The National Development and Reform Commission authorized the construction of new power plants and the expansion of the grid system, all backed by favorable financing packages offered through the state-owned banks. However, given the long construction cycle, the effects of these supply-side efforts were not felt immediately.

The purpose of our analysis is to measure the response of Chinese firms to the threat of electricity shortages. In Section 3, we account for these government demand and supply market-based policies when discussing how firms might have responded to these shortages. Namely, we are interested in the private industrial costs of electricity shortages (or more generally, regulatory-induced scarcity) rather than the overall energy costs of 
meeting demand growth. Presumably, these electricity shortages would not have occurred in a free market, whereby prices could adjust to clear the market.

\section{Firm Responses to Electricity Shortages}

Electricity is the dominant source of energy in the manufacturing sector, comprising more than $40 \%$ of primary energy consumption in the sector while coal is approximately $25 \%$. As a result, the manufacturing sector is extremely vulnerable to shortages in electricity supply. Depending upon a firm's ability to substitute to alternative forms of energy, this reliance on electricity may result in manufacturing firms taking the full brunt of electricity shortages. News reports suggested large economic costs as a result of these electricity shortages. Many of these reports were based on isolated case studies or surveys. For example, Zhejiang Province reported costs related to blackouts during 2004 to be 100 billion Yuan, or $9 \%$ of gross regional product. ${ }^{5}$ In estimating the cost of blackouts in China, Lin et al. (2005) use data from a survey that asked firms their stated willingness-to-pay to avoid an outage as well as their expenditures on backup generators. The authors estimate the marginal cost of an hour of outage to be 78,482 Yuan, or approximately USD $\$ 10,000 .^{6}$

When facing electricity shortages, firms may respond in a number of ways. The manner in which firms respond will depend, in part, on whether blackouts are planned (i.e., scheduled rationing) or unanticipated (i.e., uncertain stochastic occurrences). For example, if faced with power rationing, a firm might choose to invest in energy efficiency

\footnotetext{
${ }^{5}$ Chinese Business Times (Dec. 12, 2004) http://finance.sina.com.cn/g/20041222/03001241424.shtml1. (Accessed April 14, 2007). The article does not explain how these estimates were calculated.

${ }^{6}$ This working paper has been incorporated into Dong and $\mathrm{Li}$ (forthcoming).
} 
improvements. This would only make sense if there were quota rationing in response to electricity shortages. A second reason would be if regulators instituted policies promoting energy efficiency at the regional level. In this case, the value share of capital would likely increase while the shares of electricity and other energy inputs would fall. In contrast, capital investments may be negatively affected if power shortages reduce capital productivity or durability (Abeberese 2014).

Another common response to sustained power supply issues is for firms to invest directly in technology in order to generate electricity on site, or "self generation." In addition to the required additional capital and diesel purchases, investment in self generation will crowd out other investment opportunities, reducing productivity (Reinikka and Svensson 2002). ${ }^{7}$

In the case of self generation, other types of energy are substitutes for purchased electricity. ${ }^{8}$ This may particularly be true for industries at the top of the rolling blackouts list. During these periods of shortages, many light industries, such as food processing or textiles, were among the first to face electricity quotas. Many of these firms were reported to be working only four days a week or working during off-peak hours (Natural Resources Defense Council 2003, World Bank 2005, Thompson 2005). We expect that a firm's ability to respond by self generating may be limited in the short run. If firms expected sustained electricity shortages in the future, they may be willing to make capital investments that are potentially irreversible.

\footnotetext{
${ }^{7}$ Alby, Detherier, and Straub (2011) find self-generation increases with power outages, using firm-level data from over 80 countries. Similarly, Reinikka and Svensson (2002) find that firms invest in their own power generators when Ugandan electric power supply is unreliable and inadequate.

${ }^{8}$ Rosen and Houser (2007) and IEA (2006) reported that some firms and residents installed diesel-powered self-generation in response to the scarcity in China. This led to a $16 \%$ increase in oil demand in 2004, accounting for $27 \%$ of the increase in world oil demand that year.
} 
Another option would be for the firm to outsource the production of energyintensive, intermediate goods rather than to produce them in-house. ${ }^{9}$ Firms may decide to purchase intermediate goods rather than produce these goods from raw materials. In this case, materials would be a substitute for electricity. In addition, outsourcing could result in less use of labor, capital, and other energy sources in the production of these intermediate goods. For example, a firm requiring steel as an input to production may either purchase the raw inputs (e.g., pig iron, coal and electricity) to manufacture steel on site, or the firm may decide to purchase the steel from other producers, especially if electricity is unreliable. In this case, as these other inputs are no longer needed due to outsourcing, these inputs would be complements of electricity. Compared to self generation which could be a reasonable long-run response to sustained shortages, outsourcing could be a reasonable short-term response to electricity shortages.

Any of these three responses may lead to losses in productivity. In addition, if changing inputs is too costly in the short-run, then firms may experience losses in productivity due to reduced output. Also, extra costs may be incurred due to the need to re-arrange production schedules. Jyoti, Ozbafli, and Jenkins (2006) note that a common measure of the economic cost of blackouts is to calculate the loss in value added or in contribution (net revenue) resulting from firm-level measures of actual outage durations. These costs include labor costs, material spoilage costs, and restarting costs.

On the other hand, necessity may be the mother of invention. Firms may find ways to become more productive when resources become scarce. For example,

\footnotetext{
${ }^{9}$ This relates to literatures on supply-chain management (de Kok and Graves 2003) and on second sourcing in the face of uncertainty (Dick 1992).
} 
Borenstein and Farrell (2007) find that firms in the US gold industry exhibit xinefficiencies, which can survive in industries with barriers to entry.

In contrast to the literature, this paper examines how the threat of electricity shortages affects productivity in an immense and rapidly-growing economy, namely China. Using firm-level panel data, we study how firms respond to electricity shortages and estimate the resulting lost productivity.

Four testable hypotheses of how firms may respond to electricity shortages emerge from the discussion above:

I. Decreased Productivity: firms may have limited options to respond, implying that electricity shortages may increase unit costs.

II. Self Generation: firms may self generate, substituting away from electricity toward non-electric energy and capital.

III. Outsourcing: firms may outsource more and produce less in-house, implying more material use and less use of the other factors of production.

IV. Energy Efficiency: firms may invest in more energy efficiency technologies, for example in response to quota rationing, reducing use of both types of energy and increasing capital inputs.

\section{Data}

We test these hypotheses using a data set comprising of firm-level information on production, electricity, self generation of electricity, and out-sourcing of material inputs. 
Details on the sources of these data and the construction of key variables are provided below.

\section{Production Data}

Our empirical estimation requires firm-level production data on capital, labor, energy, and materials inputs and production costs. We construct this data set by merging two firm-level data sets. The first is a set of economic and financial survey data, collected by the National Bureau of Statistics (NBS) in China, comprising primarily large and medium firms based on sales revenue for the years 1999-2004. A second data set, also collected by the NBS for the same years, comprises information on annual energy use, both in values and physical quantities, by approximately 20 energy types. From 1999 to 2003, the data are for the largest energy-consuming firms. Notably, the last year of our sample was a census year where we have information on energy use for most medium and large firms. We also utilize industry-level data from the Chinese national accounts to construct industry-level prices of materials.

When we combine these data, we are left with an unbalanced sample of 36,943 observations from 22,902 different firms. ${ }^{10}$ As these data sets comprise repeated crosssections of survey data (and are thus a sample of the full population of firms), the set of firms included in the data set changes each year and does not necessarily include the same firms over time. The annual sample ranges from approximately 2900 in the year 2000 to about 19,000 firms in the census year, 2004 (see Panel B of Table 1). Most firms

\footnotetext{
${ }^{10}$ In the analysis below, we focus on the industrial response to electricity shortages for firms using electricity as an input. Therefore we exclude firms in the electricity generation industry (4095 observations). We exclude observations missing control variables (10,272 observations), as well as those with potential reporting errors on input prices (1274 outliers). Most of these missing variables are input prices of capital, electricity, non-electricity energy, or materials. For the outliers, we truncate at $0.5 \%$ and $99.5 \%$ of the distribution for each reported input price.
} 
report in only one year (16,899 firms), with the 2004 census year accounting for most of these observations $(15,215)$. Our analysis controls for firm fixed effects. Therefore, as discussed below, the remaining 6,003 firms that report in more than one year help identify the parameters of interest.

Panel A of Table 1 summarizes the number of firms reporting for a specific number of years - that is, there are 16,899 firms reporting in only one year while there are 731 firms reporting in all six years. Thus, if we were to use a balanced sample from 1999 to 2004 , we would be estimating based on information for 731 firms only. If we were to limit the sample to observations starting in 2000 or 2001, the balanced sample would be comprised of 898 or 1310 firms, respectively. We therefore choose to estimate our empirical model on the unbalanced sample.

A natural concern that arises with an unbalanced sample is sample selection bias. The unbalanced nature of our data set is primarily due to two factors. First, in the 2004 census, we observe about half of our sample $(15,215)$ for the first time because of their relatively low energy use. The second factor is the sampling thresholds during the other years: the economic and financial data set comprises only firms with sales revenue in excess of five million yuan (approximately $\$ 600,000$ ) and the energy data set comprises only firms that consume energy in excess of 10,000 tons standard coal equivalent (SCE). There is little actual entry of new firms, or exit of existing ones in these data sets due to the focus on large firms (Fisher-Vanden and Jefferson 2008). Rather, during the 19992003 survey years, firms near the sample cut off - either for energy use or total salesare entering and exiting the sample. As these data are not random samples, our results are 
descriptive of a sample of Chinese firms that are above these thresholds for total annual sales and total annual energy use. The importance of measuring the energy bias of electricity scarcity requires us to work with the smaller, less representative sample. Nonetheless, we test the robustness of our results by estimating our empirical model using the balanced samples mentioned above (see Appendix Table A1). A related concern is that the large number of mid-sized firms in 2004 drive the main results (that we test in Table A2). ${ }^{11}$ We explore this in our robustness tests below.

While not comprehensive, our data set comprises the largest energy-consuming firms in China. Since the energy sample criterion is based on levels and not intensity of energy consumed, the sample includes both energy intensive firms (firms with a higher energy/sales ratio) and firms that may be less energy intensive, but are large enough to consume more than 10,000 tons SCE of energy. These firms cover almost 60 percent of industrial energy use, 40 percent of sales, a third of employment, and a fifth of total assets (see Appendix Table A3). The data include firms of various private and public ownership structures. Most energy-intensive firms in capital-intensive sectors are stateowned in China. State-owned firms account for 62 percent of our data. As discussed further in Section 6 and shown in Appendix Table A4, as a robustness check, we examine whether ownership affects how firms responded to electricity shortages.

We use the combined data to explore substitution patterns across inputs beyond just capital and labor. We separate energy consumption into electricity and non-electricity

\footnotetext{
${ }^{11}$ As mentioned above, about half of the observations in our sample are for the year 2004. Since 2004 is a census year, we have energy information for almost all medium and large firms in this year-thus, there are firms in our unbalanced sample that only show up in the year 2004. The sample of year 2004 observations differ from other year samples in that firms that use less energy show up in 2004 but not in other years; e.g., the 2003 and 2004 samples have similar distributions for the value of goods sold and value added, but not for energy.
} 
energy (primarily coal and oil) and include five factor inputs in our model of production cost: labor, capital, materials, electricity, and non-electricity energy sources. Using our firm-level panel data set, we compute prices for each of the five inputs by firm and by year based on expenditures. Thus, the price of labor is the sum of the wage bill and welfare payments, divided by total employees. The price of capital, or fixed assets, is imputed from total value added minus total labor expenses, divided by net value fixed assets. The price of non-electricity energy is calculated as total other energy expenditures divided by the quantity of energy purchased in standard coal equivalent (SCE) units. The electricity price is similarly defined. In order to compute the price of materials, we use data on industrial prices by year from the China Statistical Yearbook (CSY) published by the National Bureau of Statistics. We compute the price of materials for a given firm in a specific industry as a composite of annual industry prices weighted by input-output shares for that firm's industry. Thus, firms within the same two-digit Standard Industrial Classification (SIC) industry face the same materials prices over time-i.e., these prices vary annually for each of the 37 SIC categories. In an analysis with firm fixed effects, changes in prices of non-electricity energy will reflect changes in the composition of the bundle of energy inputs into each of these categories.

Table 2 reports the summary statistics for total costs, sales revenue, factor prices and factor shares for our sample. The table reveals substantial variation in firm size. The cost of goods sold, the dependent variable in the analysis, has a mean of 446 million Yuan (approximately $\$ 50$ million) with a standard deviation of 1556 million Yuan (approximately $\$ 190$ million). The ratio of the standard deviation to the mean (the coefficient of variation) is quite large for sales revenue (the gross value of industrial 
output in constant prices) and input prices (with the exception of the price of materials), suggesting large variation in sales and input prices across firms. The large range that we observe for several input prices suggests that some outliers remain, even after truncating the sample (see footnote 10). Therefore, in the analysis below, we use the natural log of all these cost and sales variables to smooth out this heterogeneity and curtail the effect of outliers (Wooldridge 2006).

Table 2 also reports the summary statistics for the input value shares in our sample. The materials costs account for about two thirds of all costs for the median observation. Capital costs are about a sixth, followed by labor, electricity and other energy costs. The table shows substantial variation in these shares across observations.

In order to better understand the heterogeneity across industries in our sample, Table 3 reports the average factor value shares across all years in our sample for mining, food, textiles, wood products, petroleum products, chemicals, rubber, non-metal mineral products, metal products, machinery, and other industries. This table also includes firms in the electric power industry for comparison purposes only as they are not used in the analysis below. While the NBS classifies firms into 37 two-digit SIC categories, some have insufficient observations to estimate the effects by industry. Therefore, this table reflects the aggregation of two-digit SIC industries that will be used in our industryspecific estimation.

Table 3 shows that the most energy-intensive industries include petroleum processing and coking, non-metal products, chemicals, and other industries. In contrast, the food and beverage and the machinery industries spend five percent or less of their costs on energy. All industries use electricity and will be both directly and indirectly 
affected by electricity shortages. While there is not a perfect placebo test, we examine two possible candidates. First, we test whether industries that use less electricity were less sensitive to the electricity shortages. The industries with the lowest electricity shares are petroleum, machinery, and food. Second, as discussed further in Section 6, we examine a set of firms across many industries that are likely to be less energy intensive and therefore less affected by power shortages.

\section{Electricity Data}

Our estimation method, described in Section 5, requires an electricity scarcity measure. China had six main regional grids in 2002 — Central, East, North, Northeast, Northwest, and South—each encompassing several provinces. ${ }^{12}$ Power is transmitted with relative ease within a grid but has limited capability across grids. There are a number of potential electricity scarcity measures that could be considered for use in our analysis. First, we could use high-frequency (e.g., hourly) data on blackouts for each firm in our sample. Second, we could use regional (i.e., grid-level) high-frequency data and estimate the empirical distribution of the likelihood of blackouts. Third, we could proxy for this empirical distribution of the likelihood of blackouts in each region by using summary statistics (e.g., mean, variance, and deciles based on the hourly data).

Each of these measures can be problematic and thus which measure of electricity scarcity is appropriate to use in our analysis is dependent on the question we are posing. Although we would prefer to use a measure related to (2), such data are not available. Thus, we adopt a version of (3) — in particular, the ratio of thermal electricity generated to

\footnotetext{
${ }^{12}$ Grid systems in Xizang (Tibet) and Taiwan are not connected with China's national grid system and are not included in our data.
} 
thermal electricity capacity — as our measure of scarcity for reasons summarized below. We also conduct tests on alternative scarcity measures.

Firm-level, high-frequency data on the duration of each blackout period would seem ideal for our analysis. Much of the literature on the cost of blackouts, like Jyoti, Ozbafli, and Jenkins (2006), use this type of measure. However, there are several reasons why an alternative measure would be preferred in our context. Data on blackouts are limited. However, even if these data were available, using blackouts as our measure of scarcity raises the concern that provincial regulators may allocate the limited electricity to the most productive firms. By aggregating across firms within a region, we use a measure that does not suffer from this particular concern.

It is also important to consider whether a measure of blackouts is the appropriate measure to use given our research question. We are most interested in firms' responses to the threat of electricity shortages, whether or not actual blackouts occurred. Focusing only on firms that have actually experienced a blackout would cause us to miss the large number of firms that are making investments or modifications to their production process to hedge against the risk of a blackout. Most firms will not wait until a blackout occurs to take risk avoiding measures. The ratio of generation to capacity is a good measure of the potential for blackouts, as the potential of blackouts is larger the closer this ratio is to one. Lastly, it seems that our measure of scarcity would likely be correlated with blackouts. For the Eastern Grid only, we have additional data on the length and quantity of electricity interruptions. The correlation between the annual MWh curtailed and our main 
scarcity measure is 0.41 , suggesting that our measure of scarcity is a decent proxy for the duration of blackouts. ${ }^{13}$

Grid level performance indicators like capacity factors (e.g., generation/capacity) are a meaningful way to measure the extent of power system reliability, or scarcity, within a region. Within each grid, the transmission of power is frequent and with minimal congestion. However, in the absence of long distance transmission direct current lines, the transfer of electric power across grids has been difficult. As a result, in tight markets, provinces are able to provide power to other provinces located within the same regional grid through load management, but the sharing of power across grids to meet peak demand is, in most cases, impossible. Thus, the capacity factor of a specific regional grid is a decent indicator of the potential for electric power shortages within the region.

We use data on electricity scarcity constructed from information obtained from various issues of the China Electricity Yearbook. These Yearbooks contain information on electricity generation $\left(G E N_{g t}^{\text {Thermal }}\right)$ and capacity $\left(C A P_{g t}^{\text {Thermal }}\right)$ from thermal (primarily coal-fired) power plants. Our main measure of scarcity is the thermal capacity factor for grid $g$ in year $t: S_{g t}^{T h e r m a l}=G E N_{g t}^{T h e r m a l} / C A P_{g t}^{T h e r m a l}$, although we test alternative capacity measures in our analysis. ${ }^{14}$

\footnotetext{
${ }^{13}$ The correlation between annual curtailment and aggregate consumption is very high, 0.9 . This may indicate that some new capacity may not have been available in the reported year.

${ }^{14}$ For Figure 1, we adjust this variable for the number of hours in a year and account for power plant outages. Power plants typically schedule outages for maintenance and reliability purposes, sor. In addition, unscheduled outages occur due to equipment failure, for. Thus, we measure the expected annual capacity by multiplying capacity, which is in megawatts (MW) or MW-hours per hour, by (number of hours in a year)*(1-sor-for). In the econometric analysis, we take the natural logarithm of this variable so these multiplicative adjustments do not affect the estimation. The measures of sor and for are based on thermal generators of at least $100 \mathrm{MW}$ (China Electricity Yearbook, 2000). If we had power plant outage measures that varied by space and time, then this adjustment formula would be important to include in the estimation.
} 
The annual average thermal capacity factor by grid is provided in Figure $1 .{ }^{15}$ This figure shows greater scarcity in the North and East grids, and increasing scarcity in all grids over time. In the analysis below, we include year-industry and firm fixed effects. Therefore, identification of the overall effects of scarcity requires that the general upward trend in scarcity varies by region. To test this, we regress a grid's annual scarcity on grid and year fixed effects. The overall fit has an R-squared of 0.91 for our sample period, suggesting that some variation remains to identify the main results. ${ }^{16}$

This scarcity measure has the potential to reflect the overall likelihood of blackouts in a given year, which is likely to be relevant for the medium-term labor hiring, capital investment, and outsourcing decisions that we see in our firm-level productivity data. However, we considered alternative capacity factors as our measure of scarcity as well. One alternative measure is based on the single hour of a year when blackouts are most likely to occur. This is measured by the ratio of annual peak electricity consumption (MW) within a grid over total capacity: $S_{g t}^{\text {Peak }}=P e a k L o a d_{g t}^{\text {Total }} / C A P_{g t}^{\text {Total }}$, where total capacity also includes nuclear and hydropower (see Figure A2 in the Appendix). ${ }^{17}$ This measure focuses on the highest demand hour only and may be less informative of the overall probability of blackouts throughout the year. The correlation between this measure of scarcity and our preferred measure is 0.45 . We also considered a scarcity measure of the ratio of total generation over total capacity: $S_{g t}^{\text {Total }}=G E N_{g t}^{\text {Total }} / C A P_{g t}^{\text {Total }}$

\footnotetext{
${ }^{15}$ We only have firm-level data starting in 1999. However this figure reports data starting in 1997 in order to see if there is a pre-trend.

${ }^{16}$ The R-squared is 0.79 when we use all of the data (including from 1997 and 1998). Figure A1 in the Appendix plots the residuals from this regression, which show some serial correlation $(\rho=0.46)$. The North grid may seem to exhibit greater variation than the other grids. Table A4 in the Appendix reports regression results excluding firms in the North.

${ }^{17}$ For Figure A2 in the Appendix, the scarcity measure is only adjusted for unscheduled outages since maintenance would not be planned during the peak demand season.
} 
(see Figure A3 in the Appendix). We prefer the thermal capacity factor as our scarcity measure since it excludes hydropower capacity, which can be noisy relative to thermal. Namely, rainfall and river flow requirements may make the reported hydropower capacity difficult to measure. These two measures, however, are highly correlated ( correlation $=0.90)$.

Although differences do exist among the three capacity factor scarcity measures discussed above, the trends of these measures are similar. ${ }^{18}$ As the supply of electric power got tighter after 2002, all three measures point to a higher probability of the occurrence of blackouts. The pattern shown in these data were affirmed by system operators in the Eastern Grid at interviews during field work in $2007 .{ }^{19}$

Admittedly, our scarcity measure is not perfect. Namely, annual data does not allow us to examine the impact of duration, frequency, and timing of the interruptions which may affect the cost of production and the response of the firm. If the blackouts were highly concentrated in a single period of time, our alternative measure, $S_{g t}^{P e a k}$, may be better suited to capture how firms responded. Blackouts could lead plants to make an intertemporal reallocation of production, which could be costly. The appendix explores this possibility.

Our annual scarcity measure might be a modest predictor of blackouts in some regions, like the east, but poor in others. Suppose two regions had similar measures of annual scarcity but one had a milder climate with little fluctuation in demand. This region

\footnotetext{
${ }^{18}$ Appendix Table A5 examines the robustness of our main results to both of these alternative measures of scarcity.

${ }^{19}$ Interviewees suggested two additional measures for scarcity: a national, reliability index based on brownouts data in the electricity yearbooks; and the Eastern grid's data on interruptions. Neither has the regional variation and completeness of the three mentioned above.
} 
could have substantially fewer blackouts even if the annual measure of scarcity was the same as the other region. ${ }^{20}$ This suggests that our scarcity measure, as a predictor of blackouts, is likely to suffer from measurement error.

An additional concern is that firms in a region may exhibit correlated productivity shocks. For example, a regional policy could make production more profitable for all industries. This would increase demand for electricity and lead to scarcity issues. In order to address both the measurement error and the potential endogeneity of the scarcity measure, we will use instrumental variables in our main regressions.

Valid instruments will affect scarcity only through electricity demand but will not affect industrial output directly. We argue that cooling degree days (CDD) and heating degree days (HDD) — degrees above or below $65^{\circ} \mathrm{F}$, respectively — meet this criterion. Research over the past three decades has shown that demand for electricity depends on temperature. ${ }^{21}$ Regarding the exclusion restriction, we recognize that it is possible that temperature could affect workers (Yildirim et al. 2009), but argue that this effect hard to identify and likely to be second order. We constructed these instruments from global surface data provided by the National Climatic Data Center at the National Oceanic and Atmospheric Administration. These hourly data are by weather station, so we first calculate an average daily temperature for each electricity grid and then sum CDD and HDD by year and grid. ${ }^{22}$

\footnotetext{
${ }^{20}$ A related concern is over power plant outages. If a few major plants fail, our scarcity measure will decrease even though the likelihood of blackouts increases.

${ }^{21}$ See, for example, Engle et al. (1986), Pao (2006), Mansur et al. (2008), Deschenes and Greenstone (2011), Lee and Chiu (2011), and Zhou and Teng (2013).

${ }_{22}$ Most of the variation in CDD and HDD is explained by regional differences. Of the remaining variation, year fixed effects only explain $18 \%$ for CDD and $69 \%$ for HDD. The remaining variation is used to identify the effect of scarcity in the first-stage regressions.
} 


\section{Self-Generation Data}

Our analysis also requires a firm-level measure of electricity self generation. We use two direct measures of self generation in our analysis. First, our data set includes firm-level data on the amount energy used to generate electricity, which we calculate as a share of total energy consumption. We also use an indicator variable denoting any self generation. We find that about seven percent of the sample self generate. This differs dramatically from India, where blackouts are much more frequent (Allcott, CollardWexler, and O'Connell, 2014). Most self generation uses diesel while conventional power plants in China use coal and hydropower. As Southern China is farther from the northern coal mines and has little hydropower, it is not surprising that this region has a greater share of firms that self generate.

\section{Outsourcing Proxy Data}

Our analysis in Section 6 also tests for evidence of firms outsourcing in response to electricity shortages. Our main test of outsourcing, as described in Section 5, is to measure the materials bias of scarcity — that is, does scarcity lead to a greater share of materials use in production. However, we extend this test further by examining whether firms in industries that are potential suppliers of intermediate inputs experience higher growth in output as a result of electricity scarcity in a neighboring province. Although we cannot directly measure trades within China, we develop a proxy measure that is akin to the gravity model of international trade. As described below, we use the two-digit SIC industry input/output table (that we also use to calculate the price of materials) to identify upstream and downstream industries. In addition, we measure the direct distances between each pair of provinces using provincial centroids' latitudes and longitudes. 
To test whether a firm's output increases when its buyers (those in downstream industries) face greater electricity scarcity, we construct a measure of the average scarcity of other provinces where we weight a province's scarcity by the inverse of distance.

Namely, the variable for the $\log$ of a firm's Neighbor's Scarcity, $\ln S_{i t}^{n e i g h}$, is defined as:

$$
\ln S_{i t}^{n e i g h}=\left(\sum_{j=1}^{n} \ln S_{j t} / d_{i j}\right) /\left(\sum_{j=1}^{n} 1 / d_{i j}\right),
$$

where $d_{i j}$ is the distance between a firm in province $i$ and another province $j$, and $n$ is the number of provinces (other than the province in which the firm is located).

Second, we construct a variable called Downstream Responsiveness, or DownResp $p_{k}$, for industry $k$. To measure outsourcing, we want to know how a marginal shock to electricity scarcity will change the demand for materials in the downstream industry, thereby affecting the output of the upstream industry. We can think of this as the dot product of two vectors of marginal effects. The first vector is the marginal change in materials shares given a marginal change in scarcity $\left(\beta_{m a t}^{\tilde{k}}\right)$ for each industry $\tilde{k}$. We discuss how we estimate these coefficients in Section 5 and report the results in Table 5 of Section 6. The second effect is the marginal change in output in a certain (upstream) industry $k$ given a change in inputs by each (downstream) industry $\tilde{k}$ affected by the scarcity. We use the input-output value shares as a proxy of this second effect $\left(\mathrm{IO}_{k}^{h}\right)$. Thus, DownResp $p_{k}$ varies by province, year, and industry:

$$
\operatorname{DownResp}_{k}=\sum_{\tilde{k}} \beta_{m a t}^{\tilde{k}} \cdot \mathrm{IO}_{k}^{\tilde{k}}
$$

In sum, we construct a proxy of outsourcing by looking at firms in industries that are only affected by electricity shortages because their customers (who are facing these shortages) are now purchasing more intermediate goods from them. 


\section{Empirical Model}

To test the four hypotheses presented in Section 3, we begin by examining the neutral and factor-biased productivity effects of electricity shortages. From these effects, we look for evidence of reductions of productivity (Hypothesis 1), self generation (Hypothesis 2), outsourcing (Hypothesis 3), and energy efficiency improvements (Hypothesis 4). We then conduct further tests of self generation and outsourcing. Our empirical strategy is described below.

\section{Method to Measure the Effect on Productivity}

We examine the productivity response to electricity shortages by measuring both factor-neutral and factor-biased productivity effects. We specify a translog cost function to measure productivity changes. For firm $i$, input factor $j$, industry $k$, electricity grid $g$, and year $t$, we estimate the following equation:

$$
\begin{aligned}
\ln c_{i t}= & \alpha_{0} \ln S_{g t}+\alpha_{1} \ln Q_{i t} \ln S_{g t}+\beta_{j} \ln p_{\mathrm{ijt}} \ln S_{g t}+\delta_{j} \ln p_{i j t}+\pi_{\mathrm{jt}} \ln p_{i j t}+ \\
& \gamma_{\mathrm{jk}} \ln p_{i j t}+\frac{1}{2} \sum_{l=1}^{J} \varphi_{j l} \ln p_{i j t} \ln p_{i l t}+\kappa \ln Q_{i t}+\frac{\lambda}{2}\left(\ln Q_{i t}\right)^{2}+ \\
& \phi_{\mathrm{j}} \ln Q_{i t} \ln p_{i j t}+\eta_{\mathrm{i}}+\mu_{k t}+\varepsilon_{i t}
\end{aligned}
$$

where $c_{i t}$ is total production costs, $Q_{i t}$ is the gross value of industrial output (in constant prices), $p_{i j t}$ is the factor price of $j$ (where $j$ is capital, labor, materials, electricity, or other energy), and $S_{g t}$ measures electricity scarcity.

Parameters $\alpha_{0}$ and $\alpha_{1}$ measure the factor-neutral effect of scarcity (allowing the effect to vary by $Q_{i t}$ ), while $\beta_{\mathrm{j}}$ measure the factor-biased productivity effects of scarcity. For Hypothesis I, the null hypothesis is that production is not affected by scarcity either through factor adjustments or by making overall factor-neutral productivity changes; i.e., $\alpha_{0}=0$, and $\alpha_{1}=0$, and $\beta_{\mathrm{j}}=0$. 
For each factor input, we also estimate a factor value share equation (1) based on Shephard's Lemma:

$$
v s h_{i j t}=\beta_{j} \ln S_{g t}+\delta_{j}+\pi_{j t}+\gamma_{j k}+\frac{1}{2} \sum_{l=1}^{J} \varphi_{j l} \ln p_{i l t}+\phi_{\mathrm{j}} \ln Q_{i t}+\xi_{i t}
$$

Equations (1) and (2) represent a system of equations in which shocks to the factor shares are likely to be correlated across the error structure of the model. As such, we estimate equations (1) and (2) as a seemingly-unrelated regression (SUR). In order to have an invertible disturbance covariance matrix, we drop the value share equation for materials from the estimation. ${ }^{23}$

Furthermore, Shepard's Lemma and ensuring that value shares sum to one (by construction in the data) require that the coefficients exhibit the usual properties of symmetry and homogeneity of degree one in prices. Thus, we impose the following constraints on the model:

$$
\varphi_{j l}=\varphi_{l j} ; \sum_{j=1}^{J} \delta_{j}=1 ; \sum_{j=1}^{J} \beta_{j}=\sum_{j=1}^{J} \varphi_{j}=\sum_{j=1}^{J} \pi_{j}=\sum_{j=1}^{J} \gamma_{j}=\sum_{j=1}^{J} \phi_{j}=0
$$

See Fisher-Vanden and Jefferson (2008) for further discussion of these assumptions using these data and a similar specification. ${ }^{24}$ Note that even though some firms only appear

\footnotetext{
${ }^{23}$ Since the factor value shares, by construction, sum to one, we can drop one of the factor value share equations - the value share equation for materials. Coefficient estimates and standard errors will be invariant to the choice of which value share equation is dropped (see Berndt, 1991).

${ }^{24}$ We use Wald tests to estimate these assumptions (reflected in $\sim 115$ constraints in the model) in our case. We find that about half of the tests rejected the constraints. Nonetheless, we impose the symmetry restrictions on the model since the value share equations are derived from Shepard's Lemma, and therefore symmetry between the original cost function and the value share equations must hold by construction. The h.o.d. 1 in prices restrictions ensure that value shares sum to 1 , which is how value shares are defined in the data. Lastly, we adopt the translog cost function formulation as it is a flexible function that has been widely used and accepted for productivity work that tries to measure factor-biased productivity effects (see, e.g., Berndt, 1991), which is important for addressing our question of interest: how does electricity scarcity affect factor shares?
} 
once in our sample, they help identify the parameters because there are no fixed effects in the first-order equations (2) and we impose cross-equation constraints. In the analysis below, we measure the aggregate effect of scarcity on production by estimating the system of equations (1)-(2). ${ }^{25}$ Then we test for heterogeneous effects by separately estimating these equations by industry.

Economists estimate productivity effects with either production or cost functions. Both approaches may have to address concerns of endogeneity. Endogeneity concerns exist in the estimation of production functions since some input quantities could be simultaneously determined. Cost functions avoid this problem since input prices are used which are assume to be exogenously determined. We, therefore, adopt the cost function approach in our analysis which requires considering the endogeneity of output. To address this concern, we first explore potential instruments that proxy for demand shifters. While there are not a plethora of publicly available Chinese data sets, we were able to measure provincial annual population and income. Unfortunately, the first stage was weak. Therefore, instead, we use a set of firm fixed effects $\left(\eta_{i}\right)$ and industry-year fixed effects $\left(\mu_{k t}\right)$ to address the endogeneity concerns regarding output. As a robustness check, we report a model imposing constant returns to scale, akin to making the dependent variable average costs.

\footnotetext{
${ }^{25}$ If we estimate only equation (1) while imposing the constraints in equation (3), then the parameter estimates become quite noisy (though the main results lie within the 95 percent confidence interval). For these estimates, we find that predicted mean value shares differ substantially from those observed in the data. This is not the case for our main approach. Furthermore, if we estimate equation (1) without any constraints (i.e., with OLS), we find negative shares for capital and materials. Note that with a large enough sample, we would expect the estimation of only equation (1) with constraints to be consistent with our findings. However, given our sample size, we follow the literature (Berndt 1991) in estimating the system implied by Shepard's Lemma in order to improve the precision of our estimates.
} 
Throughout the paper, we instrument for scarcity to address the measurement error and endogeneity concerns mentioned in Section 4 . The weather instruments separate out CDD and HDD, as past research shows a non-monotonic relationship between electricity consumption and temperature (for example, see Mansur, Mendelsohn, and Morrison (2008) and Deschenes and Greenstone (2011)). Furthermore, we interact both weather variables with all of the variables where scarcity is in equation (1). The resulting first-stage regression is shown in equation (4):

$$
\begin{aligned}
\ln S_{g t}= & \tau_{1} C D D_{i t}+\tau_{2} H D D_{i t}+\sum_{l=1}^{J} \varphi_{j l} \ln p_{i j t} \ln p_{i l t}+\sigma_{1 j} \ln p_{\mathrm{ijt}} C D D_{i t}+ \\
& \sigma_{2 j} \ln p_{\mathrm{ijt}} H D D_{i t}+\delta_{j} \ln p_{i j t}+\pi_{\mathrm{jt}} \ln p_{i j t}+\gamma_{\mathrm{jk}} \ln p_{i j t}+ \\
& \frac{1}{2} \sum_{l=1}^{J} \varphi_{j l} \ln p_{i j t} \ln p_{i l t}+\kappa \ln Q_{i t}+\frac{\lambda}{2}\left(\ln Q_{i t}\right)^{2}+\phi_{\mathrm{j}} \ln Q_{i t} \ln p_{i j t}+\eta_{\mathrm{i}}+ \\
& \mu_{k t}+\varepsilon_{i t} .
\end{aligned}
$$

We do not impose constraints on this reduced-form equation. Typically we would incorporate this into a three-stage least squares estimation along with equations (1) and (2) while imposing constraints (3). However, given the substantial parameter estimates that include two full sets of firm fixed effects, this was not computationally feasible. Thus, we chose a seemingly-unrelated regression approach using fitted values from a first-stage instrumental variables estimation (SUR-IV) as our main specification.

In the first stage, we estimate equation (4) and predict the level of scarcity, $\ln \hat{S}_{g t}$. Appendix Table A6 reports the weather coefficient estimates, including positive and significant direct effects of both CDD and HDD on scarcity as expected. The set of instruments are strong predictors of scarcity. ${ }^{26}$ We then replace the log of scarcity, and its interactions with factor prices and the log of output, with our predicted $\ln \hat{S}_{g t}$ and the

\footnotetext{
${ }^{26}$ F-statistic is 12.4 when we cluster the standard errors at the level we measure scarcity, by grid and year. The F-statistic is 1293 if the standard errors are assumed to be i.i.d.
} 
respective interactions, in the SUR model of equations (1) and (2). This allows us to impose the constraints of equation (3) while also addressing the concern of endogeneity. We also examine a model where we do not instrument for scarcity. Results are discussed below.

Our cost function estimation allows us to compute the marginal and total effects of electricity scarcity on costs. The calculation of the marginal effect follows directly from equation (1):

$$
\frac{\partial c_{i t}}{\partial S_{g t}}=\frac{\alpha_{0} c_{i t}+\alpha_{1} \ln Q_{i t} c_{i t}}{S_{g t}}+\sum_{j=1}^{J} \frac{\beta_{j} \ln p_{i j t} c_{i t}}{S_{g t}}
$$

The first term captures the factor-neutral effects while the factor-biased effects are the remainder. Our calculations of marginal and total effects are provided below.

\section{Method to Test for Evidence of Self Generation}

Our approach to test for self generation in response to electricity shortages is twopronged. We first look for evidence of self generation in the productivity estimates described above. If firms are self-generating in response to electricity scarcity, we would expect to see a decline in the use of electricity in production, and an increase in the use of non-electricity energy and capital-i.e., the coefficient associated with the interaction of electricity and scarcity should be negative, the coefficient associated with the interaction of non-electricity energy and scarcity should be positive, and the coefficient associated with the interaction of capital and scarcity should be positive.

We test the self-generation hypothesis further by estimating separate regressions on self-generation indicators using an instrumental variables approach. The dependent variable is either the share of energy consumption that is used to generate electricity, or 
the indicator variable of self generation. For the latter, we assume a linear probability model of adoption decisions. We use the same weather variables as above. Firm and industry-year fixed effects are included in estimating (6): $:^{27}$

$$
\operatorname{Self}_{i t}=\psi_{k} \ln S_{g t}+\eta_{\mathrm{i}}+\mu_{k t}+\varepsilon_{i t}
$$

We cluster the standard errors by firm to control for serial correlation.

For each industry, we test whether a firm's decision to self generate depends on the electricity grid's scarcity measure. It is reasonable to believe that firms using a substantial amount of power are more likely to self generate when faced with electricity shortages. As our sample is of the largest energy users in China, we likely capture most of the firms that would fit this criterion. However, energy consumption is not necessarily the driving factor in a firm's decision to self generate. It could also be the case that firms would self generate if they would suffer the most from a shutdown. This includes firms in industries that need to finish a process without interruption: a blackout would mean restarting the process anew. Rather than label industries as continuous or batch producers, we estimate the effects for each industry separately. Lastly, it is important to note that the decision to self generate may differ substantially in the long run. We are only able to measure how firms responded to contemporaneous electricity shortages.

\section{Method to Test for Evidence of Outsourcing}

Similar to self generation, we take a two-pronged approach to test for outsourcing in response to electricity scarcity. We first look for evidence for outsourcing in the factor-

\footnotetext{
${ }^{27}$ Given that some firms show up only once and that this is a linear model with firm fixed effects, we drop over 16,000 observations from the single-year firms.
} 
biased productivity estimations. Outsourcing is consistent with a simultaneous reduction in the use of electricity and an increase in the purchase of materials inputs to productions.

We can also test for outsourcing on the supply side. That is, if a firm decides to outsource intermediate inputs, we should see an increase in the production of potential suppliers to this firm. To test for this, we measure how firms located in a (particularly nearby) province that is not facing scarcities are affected by electricity scarcities in other provinces. If a firm is located in an electricity grid that is not suffering electricity shortages, but is located near a newly affected province, then we would expect to see the firm increase production. This is especially true for firms that are suppliers to firms in industries that are most affected by electricity shortages.

We regress the natural logarithm of gross value of industrial output in constant prices of firm $i$ in year $t$, or output $\left(Q_{i t}\right)$, on the $\log$ of scarcity that firm $i$ faces in grid $g$ $\left(\ln S_{g t}\right)$, the $\log$ of its neighbor's scarcity $\left(\ln S_{i t}^{n e i g h}\right)$, as defined in Section 4 , and the interaction between the neighbor's scarcity and our measure of downstream responsiveness of firm $i$ in industry $k$ (DownResp $p_{k}$ ), also defined in Section 4. Similar to the self-generation regressions, we instrument for scarcity using weather data, include firm fixed effects and industry-year fixed effects, exclude firms that only report once, and cluster the standard errors by firm in estimating equation (7):

$$
\ln \left(Q_{i t}\right)=\theta_{1} \ln S_{g t}+\theta_{2} \ln S_{i t}^{\text {neigh }}+\theta_{3} \ln S_{i t}^{\text {neigh }} * \operatorname{DownResp}_{k}+\eta_{\mathrm{i}}+\mu_{k t}+\varepsilon_{i t}
$$




\section{Results}

Table 4 reports the main results from estimating the system of equations (1) and (2). The first column (SUR-IV) reports our main specification. ${ }^{28}$ Our results suggest that scarcity - defined as the ratio of generation to capacity, which captures the potential for or threat of shortages - affects how firms produce. Namely, scarcity leads to significant substitutions among the five factor inputs. Increased scarcity leads to a reduction in the use of electricity and other forms of energy and an increase in the use of materials. These results suggest that a $10 \%$ increase in scarcity will increase the cost share of materials by about two percent and will decrease the cost shares of electricity and other energy by about half that amount. The effects on labor and capital are even smaller.

This effect on materials suggests that, when electricity becomes scarce, firms will outsource the production of intermediate inputs (rather than to produce these inputs inhouse), which is consistent with our third hypothesis. We do not, however, find evidence to support our hypothesis that electricity shortages will lead to greater self generation. We observe neither an increase in capital use, nor a substitution toward other types of energy (in particular diesel oil) that would be consistent with self generation. To the contrary, we see a significant reduction in non-electric energy. At first, this effect on energy overall seems consistent with the hypothesis that electricity shortages lead to energy efficiency improvements. However, we do not see an increase in capital. Hence, outsourcing appears the only hypothesis for which we find evidence in our productivity estimates.

The overall effect on unit costs is a combination of both the factor-biased and factor-neutral effects. We explore this net effect in the following section. Table 4,

\footnotetext{
${ }^{28}$ Appendix Table A7 provides coefficient estimates for all variables excluding the firm fixed effects.
} 
however, reports a negative factor-neutral effect of scarcity-i.e., an increase in scarcity lowers the total cost of production — which suggests that, holding inputs constant, firms may have been pushed to improve overall productivity during times of scarcity. However this effect is not statistically significant. Furthermore, the effect dissipates with firm size $\left(Q_{i t}\right)$ due to the positive coefficient on the interaction of scarcity and GVIO: for the smallest firms (at $1^{\text {st }}$ percentile), the factor-neutral effect is -0.35 while the largest firms (at the $99^{\text {th }}$ percentile) the effect is only -0.01 . Both are insignificant.

The second column of Table 4 treats scarcity as exogenous by using the direct measure of scarcity and not its predicted value based on our IV regression. The coefficients are extremely similar to the main results. Nonetheless, throughout the rest of the paper, we continue with the instrumental variables approach given our concerns of measurement error and omitted variables bias previously discussed.

Columns 3 and 4 restrict the main SUR-IV specification. The third column imposes a constant factor neutral scarcity effect for firms of all sizes: i.e., $\alpha_{1}=0$ in equation (1). That is, we assume that the scarcity effect is not dependent on firm size by omitting the interaction of scarcity and GVIO from the regression. Finally, the last column assumes constant returns to scale by imposing the constraints $\alpha_{1}=0, \lambda=0$ and $\kappa=1$ in equation (1). This is akin to modeling average costs as a function of scarcity. As shown in Columns 3 and 4, imposing these restrictions does little to change the results of our main SUR-IV specification.

\section{Industry Heterogeneity}

Table 5 reports the results when we estimate the system of equations (1) and (2) separately for each industry. We find large responses to scarcity in electricity shares- 
reflected in the coefficient associated with the interaction of scarcity and electricity-for textiles, wood products, mining, and metal industries. ${ }^{29}$ Outsourcing in response to scarcity (as suggested by a positive coefficient on the interaction of scarcity and materials) is large in several sectors: wood products, chemicals, food, metal, and textiles. These results also show large decreases in other energy shares for wood products, mining, chemicals, and non-metals. The one industry that reported using more energy in response to scarcity was petroleum, which may have greater access to energy resources. Capital shares in response to scarcity fell in food and rubber, but rose substantially in mining and other industries. Labor shares in response to scarcity fell in textiles and metal. Revisiting the four hypotheses from Section 3, we find evidence of outsourcing in most industries, with the exception of mining, petroleum, rubber, and other industries. None of the industries produce results consistent with self generation. Positive factorneutral effects in the Petroleum industry—reflected in the coefficient associated with scarcity alone-imply that electricity shortages are costly for petroleum firms, and particularly costly for small petroleum firms (reflected in the negative coefficient associated with the interaction of scarcity and GVIO). In contrast, in the Rubber industry, the negative factor-neutral effect on scarcity suggests cost savings. Finally, the results in the mining industry are consistent with improved efficiency, as the coefficients associated with scarcity interacted with electricity and other energy are both negative and significant. Thus, from the first-order conditions this implies that a change in scarcity results in a decline in both the value share of electricity and other energy used in

\footnotetext{
${ }^{29}$ These industries are composite industries comprising a number of sub-industries. For instance, Wood Products include paper, pulp, and furniture manufacturing.
} 
production. Note that these differential effects across industries may be due to differences in regulatory treatment.

\section{Robustness}

We perform several robustness checks and report the findings in the appendix. As discuss in the Data section, our main specification is estimated on an unbalanced sample of firms - that is, not all firms report in every year. As a robustness check, we estimate our main specification on a balanced sample. Table A1 shows how sensitive the results are to using a balanced panel. As previously discussed, requiring that a firm report in all years vastly reduces the sample size. The second column of results shows estimate from estimating our main specification on a balanced sample of firms that report in all years between 1999-2004. We see in Column 2 that the results are qualitatively similar to our main results (replicated in Column 1). Namely, firms shift from labor and energy (both electricity and other energy) to materials. In this sample, we see some evidence of a capital-intensive factor bias from scarcity. The last two columns reduce the sample to just the balanced sample starting in 2000 and 2001, respectively. With fewer years, more firms are in these balanced samples. We see similar results with the sample starting in 2000 as with the sample starting in 1999.

In Column 2 of Table A2 we drop all 2004 observations. We find that the effects of electricity scarcity on factor shares are similar to our main results. As an additional test, we estimate the model on subsamples that exclude observations from 2004 that would be considered outliers, based on energy use in the 2003 sample. Specifically, we first truncate the sample by omitting 2004 observations where the total energy use (in heat content) in that year is below the 2003 sample minimum (resulting in 336 
observations being dropped). We create a second subsample by dropping observations in 2004 that were below the first percentile of the 2003 sample distribution (resulting in 5288 observations being dropped). As shown in columns 3 and 4 of Table A2, we find that the estimates of the effect of scarcity on factor shares are nearly identical to our main results when we estimate the model on both subsamples. We conclude that the main results seem robust to alternative samples where 2004 observations were omitted.

Table A4 presents results from several robustness checks on alternative subsamples of the data. Column 1 reports the results for the State-Owned Enterprises (SOE) only. Column 2 reports the results for non-state-owned firms. We find qualitatively similar results with both samples, with the SOE results somewhat smaller in magnitude. For example, the coefficient on materials is 0.191 in our main specification, 0.069 for SOEs, and 0.215 for other firms. The main difference is that the SOE results show a significant capital-using effect of scarcity while the non-SOE results show a significant capital-saving effect of scarcity. This averages out to an insignificant capital-saving effect in the main results.

Columns 3 and 4 of Table A4 examine regional variation. While it would be interesting to test if the main results are similar in each electricity grid, we cannot directly test this given our measure of scarcity and our specification. Namely, our scarcity measure varies over grid and year only. In addition, we include industry-year fixed effects in our analysis in order to control for unobserved trends that would be hard to justify excluding. In Column 3, we drop the region with the greatest variation, the North, and test whether there remains sufficient variation in the other regions. In the table, we see results similar to our main findings. Column 4 drops the East, which is the largest 
region. For a given level of electricity scarcity, we may believe that small regions will have a harder time responding to threats of blackouts by smoothing the scarcity over customers. When we drop the largest region, however, we do not see an increase in the parameter estimates among the smaller regions.

Table A5 tests whether our results are robust to the two alternative measures of scarcity discussed in Section 4, peak load and all capacity. The results are qualitatively similar to our main specification. However, the preferred scarcity measure shows the greatest response. This suggests that the peak measure does not capture all of the response to electricity shortages and that the measure including hydropower capacity (“all capacity") may exhibit measurement error, as discussed in Section 4.

Finally, Column 4 of Table A5 shows results for a placebo test. Recall that our energy data consists of two samples. From 1999 to 2003, we have data on just the most energy intensive firms in China. Not surprisingly, this is an unlikely group to be unaffected by electricity shortages. In Table 5, we saw that every industry changed their factor shares in some way: Even the industries that are less energy intensive, like the food and machinery industries, increased materials shares and reduced shares of electricity and of other energy. The second sample for our energy data comes from the 2004 census which includes all large and medium firms, not just the most energy intensive. We exploit this difference in sampling to construct a group of firms that are not very energy intensive: namely, the firms that show up in the 2004 only. As we have financial data on these firms, they are still medium to large in size making them a reasonable control group. The downside is that we only observe these firms once and therefore need to adopt a cross sectional approach to our estimation. We drop the firm fixed effects and include 
time-invariant controls including indicators of industry and ownership. The table shows that none of the factor bias effects of scarcity are significantly different from zero. Therefore, we do not find evidence of outsourcing in response to electricity scarcity among firms that are less energy-intensive. Since only the most energy-intensive firms experience a drop in the use of electricity and an increase in the purchases of materials, this bolsters our belief that firms that are most exposed to electricity shortages are responding by outsourcing.

\section{Self Generation}

Table 6 reports the estimates of equation (6) on self generation by industry. The first panel examines the indicator variable of self generation. The coefficients are large for many industries, but the estimates are noisy. For example, mining and food both have positive coefficients suggesting greater self generation during greater times of scarcity, but the estimates are insignificant at the $10 \%$ level. We do find significant, but negative, effects for wood products, chemical, metal, and other industries. These findings are consistent with our cost function results, which do not support the hypothesis that firms chose to self generate in reaction to electricity shortages (Hypothesis II in Section 3). Table 6 also includes the mean of the dependent variable. We see that self generation is most common in mining, food, and petroleum. Even in these industries, less than $20 \%$ of firms self generate.

Panel B of Table 6 reports the results when the dependent variable is the share of energy consumption used to generate electricity. Again, the estimates are noisy. The largest positive effects are in non-metal and mining but are insignificant. In these regressions, we find negative coefficients on the self-generation rate, which are 
statistically significant at the 5\% level, for chemicals and metal industries, suggesting that scarcity leads to less self generation in these industries. We report the mean of the dependent variable and see that no industry uses more than eight percent of its total energy consumption to generate electricity.

We conclude that the firms in our sample do not self generate electricity often, and, even those with the capability, do not depend on self generation to supply power. We find no evidence consistent with firms investing in generators to address electricity shortages.

Appendix Table A8 provides robustness tests of the results, pooling across all industries (i.e. for the average firm across industries), using alternative models. Columns 1 and 3 estimate the effects for our two measures of self generation (the indicator and share variables, respectively) using the model used in Table 6-i.e., a linear model with firm fixed effects - but pooled across industries. In Column 2, we drop the firm fixed effects and estimate a random effects probit model where we include time-invariant indicator variables for region, industry, and ownership. In Column 4, we estimate a random effects Tobit model with similar controls. In all specifications, we find no evidence of self generation.

Note that these effects are identified off of just a few years of data, contemporaneous with the height of the power shortages. Installing new capital-intensive equipment might require more time to install. Similarly, firms may have been waiting to determine whether or not these electricity shortages would become persistent: there was option value in waiting. Finally, while there were reports of firms and residents installing self generation (Rosen and Houser 2007, IEA 2006), our sample focuses on just the 
largest energy users. For these firms, the costs of self supplying may have been extremely large. These are reasonable explanations for the lack of evidence of self generation in our results.

\section{Outsourcing}

As a further test of outsourcing, we estimate whether a firm's production increases when firms it supplies to are facing electricity shortages (namely, equation (7)). The results are provided in Table 7. In Column 1, we include only the firm's own scarcity and its neighbor's scarcity. We find evidence that firms increase output when either the $\log$ of their own scarcity decreases or the log of their neighbor's scarcity increases. A one standard deviation increase in own scarcity leads to a $11 \%$ decrease in output, while a one standard deviation increase in the neighbor's scarcity leads to a $21 \%$ increase in output. ${ }^{30}$

Column 2 of Table 7 shows the effect of own scarcity and the interaction term between neighbor's scarcity and downstream responsiveness. In effect, this increases the weight of those observations that are most likely to experience outsourcing, as their buyers are in industries that had the largest change in materials shares in response to increased electricity scarcity. Here we see the effect of own scarcity is less than half the magnitude of the coefficient in Column 1, though still significant. However, the interaction term of downstream responsiveness and neighbor's scarcity is large and significant. A one standard deviation increase in this variable leads to a $26 \%$ increase in output.

\footnotetext{
${ }^{30}$ For brevity, we stop referring to the log specification, hereafter. The standard deviations of the three variables are 0.104 for own scarcity, 0.079 for the neighbor's scarcity, and 0.028 for the interaction term.
} 
Finally, in Column 3 of Table 7, we include all three variables. Note that we do not also include the downstream responsiveness variable as it is perfectly correlated with the firm fixed effects. This specification tests for a differential impact in the response to neighbor's scarcity. We find results consistent with Column 1 for the own scarcity and neighbor's scarcity, and a coefficient consistent with Column 2 for the interaction term. Namely, a one standard deviation in own scarcity, neighbor's scarcity, and neighbor's scarcity interacted with downstream responsiveness result in a $-11 \%, 17 \%$ and $23 \%$ change in a firm's output, respectively. However, only the coefficients on own scarcity and the interaction of neighbor's scarcity with downstream responsiveness are significant (at the 10\% level). These results lend further evidence that scarcity leads firms to outsource.

\section{The Costs of Shortages}

How did electricity shortages during 2000-2004 affect total production costs? Table 8 provides estimates of the change in aggregate production costs—in both Yuan and approximate US\$ — holding output fixed, as a result of changes in scarcity from 1999 onward. To calculate this, we first compute the marginal cost of scarcity using equation (5) with estimated coefficients from Table 5 and sample means for the independent variables. We report these marginal effects in Column 1 of Panel A. Overall, the marginal cost is 391 million Yuan. We then disaggregate this into the factor bias effect (first term of equation (5)) and the factor neutral effect (second term of equation (5)), which are 510 and -118 million Yuan, respectively. These results imply that while shifting factor input shares in response to a marginal increase in electricity scarcity lowers cost, loses in 
overall productivity from a marginal increase in scarcity offset these gains. We further disaggregate the factor bias effect for each of the five factors. We find that the shift to materials in response to a marginal change in scarcity increases costs by 667 million Yuan, with shifts away from labor, electricity and other energy partially offsetting this cost increase.

Next we calculate the change in total production costs that we attribute to the actual change in scarcity. In other words, had China continued to build power plants allowing electricity supply to grow at the same rate as the quantity demanded grew from 1999 to 2004, how much would firms had saved in unit production costs? To estimate this, we multiply the marginal cost of scarcity by the actual change in scarcity from 1999 to each subsequent year, and aggregate over all observations in our sample. As shown in Column 2 of Table 8, Panel A, we find that total costs increased by 1192 billion Yuan, or $7.8 \%$ of the total realized aggregate costs of these firms from 2000 to 2004. Factor biased effects account for this increase, with total costs increasing by 1552 billion Yuan (10.1\% of aggregate costs) due to these factor biased effects. In particular, the shift to materials increased total production costs by 2032 billion Yuan (13.2\% of aggregate costs).

Panel B of Table 8 repeats these calculations using the marginal effects calculated separately for each observation. That is, equation (5) is evaluated using estimated coefficients from Table 5 and observational data for the variables. Panel B reports the mean of these calculated marginal effects by observation. Given that equation (5) is not linear in variables, some differences from Panel A are expected. Nonetheless, the first column of this table reports that the means of the marginal effects are similar to those in Panel A. From 2000 to 2004, total costs increased by 1316 billion Yuan (8.6\% of all 
costs). As in the top panel, most of this is attributed to materials expenses: 1918 billion Yuan $(12.5 \%$ of all costs).

We can use the results from Table 8 to calculate the benefits, due to fewer productivity losses, of reducing electricity scarcity. From Panel A, the marginal benefit of reducing scarcity is 391 million Yuan for the average firm in our sample. From 2000 to 2004, Chinese electricity grids had, on average, 44 GW of fossil capacity. Suppose that a one MW power plant were built and operated with a 50 percent capacity factor (generating, on average, $0.5 \mathrm{MWh}$ per hour). For the average grid, this would reduce scarcity by about $1 / 88,000$. Our sample has 1,026 firms reporting in each grid and year, on average. Aggregating over these firms, we calculate that building an additional MW of capacity would reduce productivity losses by about 4.6 million Yuan per year, or USD $\$ 103$ per MWh. Note that these are short run costs that were unexpected. Had firms known of these risks, they may have invested in more self generation. ${ }^{31}$ In contrast, the International Energy Agency (2010) estimates that a new one MW Chinese coal plant would cost 3.8 million Yuan to build, with levelized costs of $\$ 33$ per MWh. On the margin, the productivity benefits exceed the private costs of building a new power plant.

\section{Conclusion}

This paper examines how firms in China responded to power shortages during the early 2000s. We find that firms in regions with greater shortages decreased factor shares of electricity and increased shares of materials. We do not find evidence of an increase of

\footnotetext{
${ }^{31}$ Distributed generation levelized costs range from $\$ 90$ to $\$ 220 / \mathrm{MWh}$ : see http://www.eia.gov/oiaf/archive/aeo09/pdf/0383(2009).pdf and http://srren.ipcc-wg3.de/report/, respectively.
} 
self generation of electricity. In fact, we find an overall decrease in other non-electricity energy sources, suggesting that these primary energy sources are complementary inputs in producing the intermediate products that have been outsourced in response to electricity shortages. The overall effect of electricity shortages, which we proxy for with a measure of scarcity, was to increase production costs. From 1999 to 2004, firms' costs rose by eight percent, primarily due to input factor substitutions.

Policy recommendations in light of these results are difficult to determine and are beyond the scope of this paper. Although our results would seem to suggest that more power plants should have been built, this conclusion could only be made by trading off the social cost of building new power plants with the benefits (e.g., the avoidance of productivity losses from electricity scarcity). As discussed in Section 7, we calculate that a one MW power plant could result in benefits in improved productivity each year that are over 400 times greater than the levelized construction costs.

Policy makers would also want to consider other mechanisms to provide reliable service. For example, dynamic pricing that reflects electricity firms' actual marginal costs would be an option. While we do not address these questions, our results help determine how costly the electricity shortages were in China between 1999 and 2004. 


\section{References}

Abeberese, Ama Baafra. 2014. "The Effect of Electricity Shortages on Firm Investment: Evidence from Ghana," Manuscript, Wellesley College.

Alby, Philippe, Jean-Jacques Detherier, and Sèphane Straub. 2011. "Let There be Light!

Firms Operating under Electricity Constraints in Developing Countries," Toulouse School of Economics Working Paper 11-255.

Allcott, Hunt, Allan Collard-Wexler, and Stephen D. O'Connell. 2014. "How Do

Electricity Shortages Affect Productivity? Evidence from India," Manuscript, New York University.

Baisa, Brian, Lucas Davis, Stephen Salant, and William Wilcox. 2010. "The Welfare

Costs of Unreliable Water Service," Journal of Development Economics, 92(1), 112.

Berndt, Ernst R. 1991. The Practice of Econometrics: Classic and Contemporary. Addison-Wesley Publishing Co.

Borenstein, Severin and Joseph Farrell. 2007. "Do Investors Forecast Fat Firms?

Evidence from the Gold Mining Industry," Rand Journal of Economics, 38(3): 626647.

Chen, Lijuan, and Lixiong Jia. 2006. "Reliability of Nationwide Transmission and Substation Facilities and Urban Consumer's Power Supply in 2005," Electricity, 3: 45-51.

de Kok, A.G. and S.C. Graves, eds. 2003. Handbook in Operations Research and Management Science: Supply Chain Management: Design, Coordination and Operation, Volume 11, Elsevier, Amsterdam.

Deschenes, Olivier and Michael Greenstone. 2011. "Climate Change, Mortality, and Adaptation: Evidence from Annual Fluctuations in Weather in the US," American Economic Journal: Applied Economics, 3(4): 152-185.

Dick, Andrew. 1992. "An Efficiency Explanation for Why Firms Second Source," Economic Inquiry, 30(2): 332-354.

Dong, Baomin and Xuefeng Li. Forthcoming. "Estimating Outage Costs in China: A Modified Tobit Model," Emerging Markets Finance and Trade.

Energy Information Administration (EIA). 2009. International Energy Outlook, 2009. U.S. Department of Energy, Washington, DC.

Engle, Robert F., C. W. J. Granger, John Rice, and Andrew Weiss. 1986.

"Semiparametric Estimates of the Relation between Weather and Electricity Sales," Journal of the American Statistical Association, 81(394): 310-320.

Fisher-Vanden, Karen. 2009. "Energy in China: Past Trends and Future Directions," International Review of Environmental and Resource Economics, 3(3): 217-244.

Fisher-Vanden, Karen, and Gary Jefferson. 2008. "Technology Diversity and Development: Evidence from China's Industrial Enterprises," Journal of Comparative Economics, 36(4): 658-672.

International Energy Agency (IEA). 2006. "China's Power Sector Reforms: Where to Next?" Paris: OECD.

IEA. 2007. "World Energy Outlook, 2007: China and India Insights," Paris: OECD.

IEA. 2010. "Projected Costs of Generating Electricity," OECD/IEA, Paris, http://www.iea.org/publications/freepublications/publication/projected_costs.pdf. 
Jyoti, Roop, Aygul Ozbafli, and Glenn Jenkins. 2006. "The Opportunity Cost of Electricity Outages and Privatization of Substations in Nepal," Queen's University, Department of Economics, Working Paper \#1066, 24 pp.

Lee, Chien-Chiang, and Yi-Bin Chiu. 2011. "Electricity Demand Elasticities and Temperature: Evidence from Panel Smooth Transition Regression with Instrumental Variable Approach,” Energy Economics, 33(5): 896-902.

Lin, B., B. Dong, and X. Li. 2005. "An Econometric Analysis on the Power Shortages and Outages." Manuscript, Department of Economics, University of International Business and Economics, Beijing, China.

Mansur, Erin T., Robert Mendelsohn, and Wendy Morrison. 2008. "Climate Change Adaptation: A Study of Fuel Choice and Consumption in the US Energy Sector," Journal of Environmental Economics and Management \}, 55(2): 175-193.

Natural Resources Defense Council. 2003. "Demand Side Management in China: Benefits, Barriers, and Policy Recommendations." www.nrdc.org/air/energy/chinadocs/dsm.pdf. Accessed April 02, 2007.

National Bureau of Statistics (NBS). 2007. "China Statistical Yearbook, 2007,” Beijing, PR China.

Pao, H.-T. 2006. "Comparing Linear and Nonlinear Forecasts for Taiwan's Electricity Consumption," Energy 31, 2129-2141.

Reinikka, Ritva and Jakob Svensson. 2002. "Coping with Poor Public Capital," Journal of Development Economics, 69: 51-69.

Rosen, D.H., and T. Houser. 2007. "China Energy: A Guide for the Perplexed," Peterson Institute for International Economics, Washington, DC.

Thompson, E. 2005. "Power Shortages in China: Why?" China: An International Journal, 3(1): 155 -- 171. http://muse.jhu.edu/journals/china/v003/3.1thomson.pdf. Accessed on April 13, 2007.

Wang, Juliana Qiong. 2007. "Background Paper: The Power Sectors in China -Development, Reform, and Shortages." Manuscript, Yale University.

Wooldridge, Jeffrey M. 2006. Introductory Econometrics: A Modern Approach, third edition. Cincinnati, OH: South-Western

College Publishing.

World Bank. 2005. "Demand-Side Management in China's Restructured Power Industry: How Regulation and Policy Can Deliver Demand-Side Management Benefits to a Growing Economy and a Changing Power System." Energy Sector Management Assistance Program.

Yildirim, Kemal, Cuneyt Koyuncu, and Julide Koyuncu. 2009. "Does Temperature Affect Labor Productivity: Cross-Country Evidence," Applied Econometrics and International Development 9.1: 29-38.

Zhou, Shaojie, and Fei Teng. 2013. "Estimation of Urban Residential Electricity Demand in China using Household Survey Data," Energy Policy 61: 394-402. 


\section{Tables and Figures}

Table 1: Summary of Unbalanced Panel

Panel A: Number of Years Observed for a Given Firm

\begin{tabular}{rrr} 
Years & No. Firms & $\begin{array}{r}\text { No. of } \\
\text { Observations }\end{array}$ \\
\hline 1 & 16,899 & 16,899 \\
2 & 2,448 & 4,896 \\
3 & 1,227 & 3,681 \\
4 & 904 & 3,616 \\
5 & 693 & 3,465 \\
6 & 731 & 4,386 \\
Total & 22,902 & 36,943
\end{tabular}

Panel B: Sample Size per Year

\begin{tabular}{rr} 
Year & Sample Size \\
\hline 1999 & 3,325 \\
2000 & 2,907 \\
2001 & 3,318 \\
2002 & 3,729 \\
2003 & 4,576 \\
2004 & 19,088
\end{tabular}

Notes: Panel A reports the number of years that we observe each firm. For example, 904 firms report in four year, accounting for 3616 observations. In Panel B, we report the number of firms reporting in each calendar year. We see that the 2004 census accounts for about half of our sample. 
Table 2: Summary Statistics of Cost Data

\begin{tabular}{|c|c|c|c|c|c|c|}
\hline Variables & Description & Mean & $50^{\text {th }}$ & $\begin{array}{r}\text { Standard } \\
\text { Deviation }\end{array}$ & Min & Max \\
\hline Costs & total cost ( $¥$ million) & 446 & 124 & 1,556 & 0 & 68,700 \\
\hline Output & gross value in constant prices ( $¥$ million) & 468 & 136 & 1,732 & 1 & 74,800 \\
\hline vshK & value share of capital (\%) & $18 \%$ & $16 \%$ & $12 \%$ & $0 \%$ & $96 \%$ \\
\hline vshL & value share of labor $(\%)$ & $7 \%$ & $6 \%$ & $6 \%$ & $0 \%$ & $74 \%$ \\
\hline vshM & value share of materials (\%) & $62 \%$ & $64 \%$ & $15 \%$ & $0 \%$ & $98 \%$ \\
\hline vshElect & value share of electricity $(\%)$ & $6 \%$ & $3 \%$ & $8 \%$ & $0 \%$ & $84 \%$ \\
\hline vshNelect & value share of non-electric energy $(\%)$ & $6 \%$ & $2 \%$ & $10 \%$ & $0 \%$ & $97 \%$ \\
\hline $\mathrm{pK}$ & price of capital (see text) & 0.88 & 0.43 & 1.47 & 0.01 & 17.35 \\
\hline $\mathrm{pL}$ & price of labor ( $¥ 1000 /$ person) & 14.81 & 12.28 & 9.73 & 1.67 & 80.33 \\
\hline $\mathrm{pM}$ & price of materials (see text) & 91.81 & 90.73 & 5.61 & 78.10 & 119.10 \\
\hline pElect & price of electricity ( $¥ 1000 / \mathrm{mwh}$ ) & 6.75 & 5.40 & 7.37 & 0.27 & 62.00 \\
\hline pNelect & price of non-electric energy ( $¥ 1000 /$ sce) & 1.17 & 0.70 & 1.20 & 0.03 & 13.60 \\
\hline
\end{tabular}

Notes: Sample size is $36,943$. 
Table 3: Average Value Shares by Industry

\begin{tabular}{|c|c|c|c|c|c|c|c|}
\hline Industry & 2-digit SIC & Obs. & Capital & Labor & Materials & Elect & Non-Elect \\
\hline Mining & $06-10,12$ & 1,910 & $24 \%$ & $16 \%$ & $46 \%$ & $7 \%$ & $6 \%$ \\
\hline Food and Beverage & $13-16$ & 3,542 & $25 \%$ & $6 \%$ & $64 \%$ & $2 \%$ & $3 \%$ \\
\hline Textile, Apparel, and Leather Products & $17-19$ & 4,873 & $16 \%$ & $9 \%$ & $68 \%$ & $5 \%$ & $2 \%$ \\
\hline Wood Products & $20-24$ & 2,282 & $18 \%$ & $7 \%$ & $64 \%$ & $6 \%$ & $5 \%$ \\
\hline Petroleum Processing and Coking & 25 & 766 & $13 \%$ & $3 \%$ & $45 \%$ & $1 \%$ & $38 \%$ \\
\hline Chemicals & $26-28$ & 6,160 & $16 \%$ & $6 \%$ & $59 \%$ & $9 \%$ & $10 \%$ \\
\hline Rubber and Plastic Products & $29-30$ & 1,127 & $18 \%$ & $7 \%$ & $69 \%$ & $4 \%$ & $2 \%$ \\
\hline Non-Metal Products & 31 & 5,040 & $17 \%$ & $7 \%$ & $53 \%$ & $11 \%$ & $12 \%$ \\
\hline Metal Processing and Products & $32-34$ & 2,993 & $16 \%$ & $5 \%$ & $65 \%$ & $6 \%$ & $7 \%$ \\
\hline Machinery, Equipment, and Instruments & $35-37,39-42$ & 7,682 & $18 \%$ & $8 \%$ & $70 \%$ & $2 \%$ & $1 \%$ \\
\hline Electric Power & 44 & 1,351 & $23 \%$ & $8 \%$ & $47 \%$ & $6 \%$ & $15 \%$ \\
\hline Other Industry & $43,45,46$ & 568 & $24 \%$ & $13 \%$ & $43 \%$ & $13 \%$ & $6 \%$ \\
\hline
\end{tabular}

Notes: Sample size is 36,943 plus 1,351 electric power firms for comparison only. Wood products include timber, furniture, and paper products. Other industries include other manufacturing products (SIC 43) and gas production and supply (SIC 45-46). 
Table 4: The Cost of Electricity Reliability

Dependent Variable: Log of Total Costs by Firm and Year

\begin{tabular}{|c|c|c|c|c|}
\hline Variable & SUR-IV & SUR & No Interaction & Impose CRS \\
\hline \multirow[t]{2}{*}{$\ln (\mathrm{P}$ capital $) * \ln ($ scarcity $)$} & -0.006 & -0.008 & -0.006 & 0.001 \\
\hline & $(0.008)$ & $(0.008)$ & $(0.008)$ & $(0.008)$ \\
\hline \multirow[t]{2}{*}{$\ln ($ wage $) * \ln ($ scarcity $)$} & $-0.028 * * *$ & $-0.027 * * *$ & $-0.028 * * *$ & $-0.029 * * *$ \\
\hline & $(0.004)$ & $(0.004)$ & $(0.004)$ & $(0.004)$ \\
\hline \multirow[t]{2}{*}{$\ln (\mathrm{P}$ materials $) * \ln ($ scarcity $)$} & $0.191 * * *$ & $0.184 * * *$ & $0.191 * * *$ & $0.196 * * *$ \\
\hline & $(0.012)$ & $(0.011)$ & $(0.012)$ & $(0.012)$ \\
\hline \multirow[t]{2}{*}{$\ln ($ P electricity $) * \ln ($ scarcity $)$} & $-0.060 * * *$ & $-0.057 * * *$ & $-0.060 * * *$ & $-0.066 * * *$ \\
\hline & $(0.006)$ & $(0.006)$ & $(0.006)$ & $(0.006)$ \\
\hline \multirow[t]{2}{*}{$\ln ($ P other energy $) * \ln ($ scarcity $)$} & $-0.096 * * *$ & $-0.092 * * *$ & $-0.096 * * *$ & $-0.101 * * *$ \\
\hline & $(0.007)$ & $(0.007)$ & $(0.007)$ & $(0.007)$ \\
\hline \multirow[t]{2}{*}{$\ln$ (scarcity) } & -0.871 & -1.050 & $-0.202 *$ & -0.186 \\
\hline & $(0.835)$ & $(0.701)$ & $(0.122)$ & $(0.122)$ \\
\hline \multirow[t]{2}{*}{$\ln (\mathrm{GVIO}) * \ln ($ scarcity $)$} & 0.055 & 0.039 & & \\
\hline & $(0.068)$ & $(0.057)$ & & \\
\hline \multirow[t]{2}{*}{$\ln (\mathrm{GVIO})$} & $0.593 * * *$ & $0.588 * * *$ & $0.554 * * *$ & 1 \\
\hline & $(0.060)$ & $(0.052)$ & $(0.035)$ & \\
\hline Average TFP Effect & -0.217 & -0.586 & -0.202 & -0.186 \\
\hline
\end{tabular}

Notes: Regressions include firm fixed effects, industry*year fixed effects, and factor prices by year. Standard errors are reported in parentheses. We denote significance at the $10 \%\left(^{*}\right)$, $5 \%(* *)$, and $1 \%(* * *)$ levels. The sample has 36,943 observations from 22,902 firms.

GVIO is gross value of industrial output. In Column (1), we instrument for scarcity using quadratic functions of cooling degree days and heating degree days. Column 2 treats scarcity as exogenous. Column 3 does not include $\ln (\mathrm{GVIO}) * \ln ($ scarcity). Column 4 imposes constant returns to scale which implies that the coefficient on $\ln (\mathrm{GVIO}) * \ln$ (scarcity) is zero and the coefficient on $\ln (\mathrm{GVIO})$ is one. 


\section{Table 5: Industry-Specific Cost Effects of Electricity Reliability}

\begin{tabular}{|c|c|c|c|c|c|c|c|c|c|c|c|c|}
\hline \multirow{3}{*}{$\frac{\text { ariable }}{(\mathrm{P} \text { capital }) * \ln (\text { scarcity })}$} & \multicolumn{2}{|l|}{ Mining } & \multicolumn{2}{|l|}{ Food } & \multicolumn{2}{|l|}{ Textiles } & \multicolumn{2}{|l|}{ Products } & \multicolumn{2}{|c|}{ Petroleum } & \multicolumn{2}{|c|}{ Chemical } \\
\hline & 0.23 & $* * *$ & -0.14 & $* * *$ & 0.04 & & -0.08 & $* *$ & -0.08 & $*$ & -0.03 & $* *$ \\
\hline & $(0.04)$ & & $(0.03)$ & & $(0.02)$ & & $(0.03)$ & & $(0.04)$ & & $(0.02)$ & \\
\hline \multirow[t]{2}{*}{ (wage)*ln(scarcity) } & 0.02 & & -0.01 & & -0.11 & $* * *$ & 0.04 & $*$ & -0.04 & $* *$ & -0.02 & $* * *$ \\
\hline & $(0.03)$ & & $(0.01)$ & & $(0.02)$ & & $(0.02)$ & & $(0.02)$ & & $(0.01)$ & \\
\hline \multirow[t]{2}{*}{ (P materials)*/n(scarcity) } & 0.01 & & 0.23 & $* * *$ & 0.20 & $* * *$ & 0.35 & $* * *$ & -0.08 & & 0.25 & $* * *$ \\
\hline & $(0.05)$ & & $(0.04)$ & & $(0.03)$ & & $(0.05)$ & & $(0.07)$ & & $(0.03)$ & \\
\hline \multirow[t]{2}{*}{ (P electricity)* $\ln ($ scarcity) } & -0.08 & $* * *$ & -0.02 & $* *$ & -0.13 & $* * *$ & -0.11 & $* * *$ & -0.02 & $*$ & -0.06 & $* * *$ \\
\hline & $(0.02)$ & & $(0.01)$ & & $(0.01)$ & & $(0.02)$ & & $(0.01)$ & & $(0.02)$ & \\
\hline \multirow[t]{2}{*}{$(\mathrm{P}$ other energy)* $\ln$ (scarcity) } & -0.18 & $* * *$ & -0.05 & $* * *$ & 0.00 & & -0.19 & $* * *$ & 0.22 & $* * *$ & -0.14 & $* * *$ \\
\hline & $(0.03)$ & & $(0.01)$ & & $(0.01)$ & & $(0.02)$ & & $(0.08)$ & & $(0.02)$ & \\
\hline \multirow[t]{2}{*}{ (scarcity) } & 2.66 & & 1.29 & & -0.94 & & -1.74 & & 9.57 & $* * *$ & -4.64 & $*$ \\
\hline & $(2.61)$ & & $(1.96)$ & & $(6.18)$ & & $(2.40)$ & & $(3.27)$ & & $(2.72)$ & \\
\hline \multirow[t]{2}{*}{$(\mathrm{GVIO}) * \ln ($ scarcity $)$} & -0.11 & & -0.23 & & 0.10 & & 0.02 & & -0.51 & $* *$ & 0.35 & \\
\hline & $(0.22)$ & & $(0.16)$ & & $(0.50)$ & & $(0.20)$ & & $(0.26)$ & & $(0.22)$ & \\
\hline \multirow[t]{2}{*}{ (GVIO) } & 0.58 & $* * *$ & 0.29 & $* *$ & 0.69 & $*$ & 0.70 & $* * *$ & 0.26 & & 0.82 & $* * *$ \\
\hline & $(0.16)$ & & $(0.12)$ & & $(0.35)$ & & $(0.15)$ & & $(0.17)$ & & $(0.16)$ & \\
\hline
\end{tabular}

Panel B: Rubber, Non-Metal, Metal, Machinery, and Other Industries

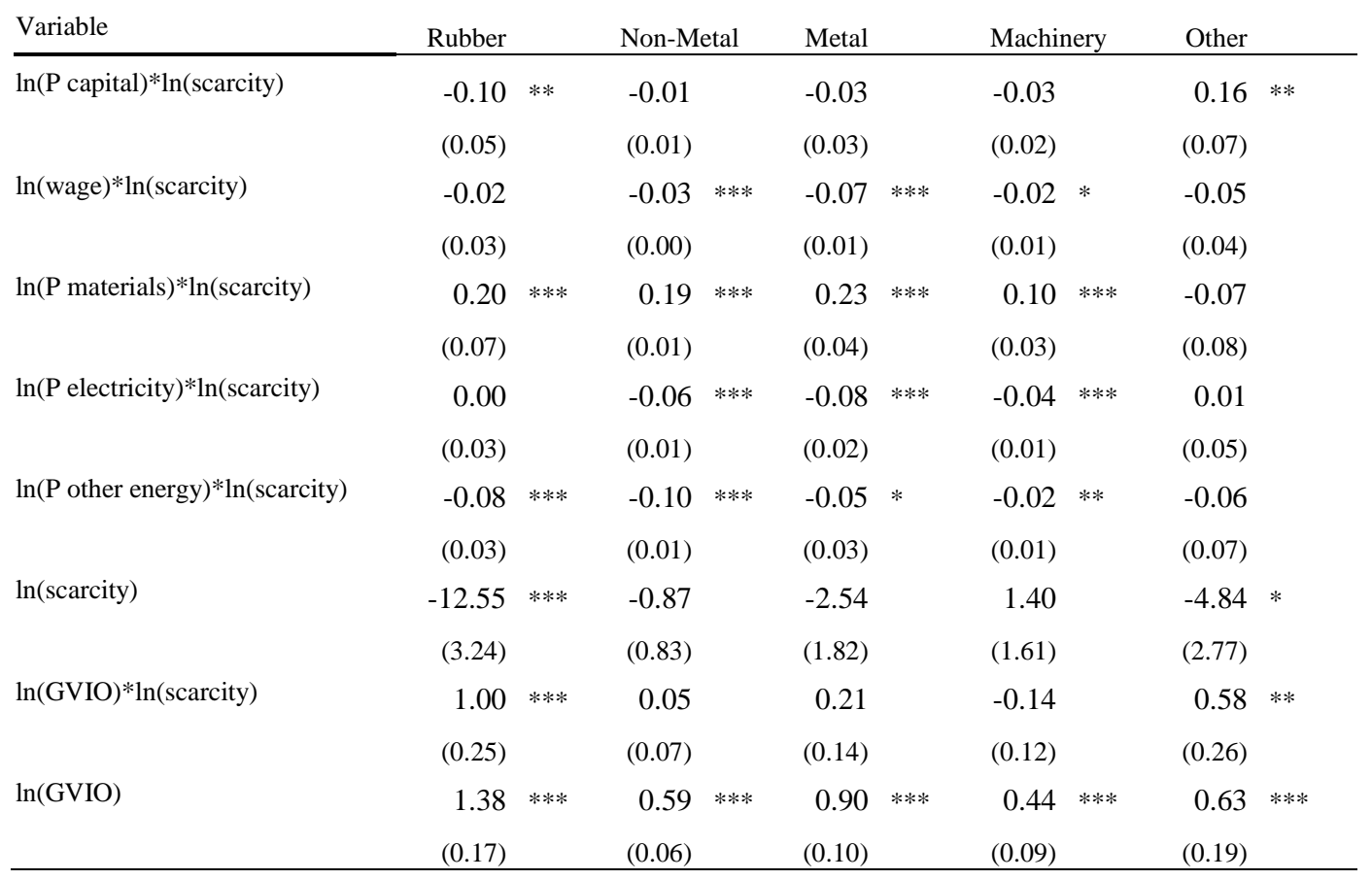

Notes: This regression follows Table 4, Column 1, but allows the coefficients to vary by industry. 
Table 6: Testing for Self Generation

Panel A: Dependent Variable is an Indicator of Self Generation

\begin{tabular}{|c|c|c|c|c|c|c|c|c|c|c|c|}
\hline & Mining & Food & Textiles & $\begin{array}{c}\text { Wood } \\
\text { Products }\end{array}$ & Petroleum & Chemical & Rubber & Non metal & Metal & Machinery & Other \\
\hline $\ln$ (scarcity) & $\begin{array}{c}0.211 \\
(0.353)\end{array}$ & $\begin{array}{c}0.036 \\
(0.285)\end{array}$ & $\begin{array}{l}-0.164 \\
(0.170)\end{array}$ & $\begin{array}{c}-1.097 * * * \\
(0.261)\end{array}$ & $\begin{array}{l}-0.222 \\
(0.414)\end{array}$ & $\begin{array}{c}-0.311 * * \\
(0.142)\end{array}$ & $\begin{array}{l}-0.307 \\
(0.267)\end{array}$ & $\begin{array}{c}0.003 \\
(0.087)\end{array}$ & $\begin{array}{c}-0.719 * * \\
(0.299)\end{array}$ & $\begin{array}{l}-0.082 \\
(0.116)\end{array}$ & $\begin{array}{c}-0.503 * * \\
(0.236)\end{array}$ \\
\hline Observations & 1,910 & 3,542 & 4,873 & 2,282 & 766 & 6,160 & 1,127 & 5,040 & 2,993 & 7,682 & 568 \\
\hline \# Firms & 1,078 & 2,145 & 3,292 & 1,424 & 399 & 3,039 & 778 & 2,444 & 1,886 & 6,182 & 235 \\
\hline Mean Dep Var & 0.197 & 0.126 & 0.036 & 0.102 & 0.188 & 0.098 & 0.018 & 0.025 & 0.094 & 0.012 & 0.026 \\
\hline
\end{tabular}

Panel B: Dependent Variable is the Share of Total Energy Consumption Used to Generate Electricity

\begin{tabular}{|c|c|c|c|c|c|c|c|c|c|c|c|}
\hline & Mining & Food & Textiles & $\begin{array}{c}\text { Wood } \\
\text { Products }\end{array}$ & Petroleum & Chemical & Rubber & Non metal & Metal & Machinery & Other \\
\hline $\ln$ (scarcity) & $\begin{array}{c}0.069 \\
(0.197)\end{array}$ & $\begin{array}{l}-0.061 \\
(0.229)\end{array}$ & $\begin{array}{c}-0.002 \\
(0.096)\end{array}$ & $\begin{array}{c}-0.281 * \\
(0.160)\end{array}$ & $\begin{array}{l}-0.075 \\
(0.077)\end{array}$ & $\begin{array}{c}-0.274 * * * \\
(0.067)\end{array}$ & $\begin{array}{l}-0.006 \\
(0.067)\end{array}$ & $\begin{array}{c}0.373 \\
(0.447)\end{array}$ & $\begin{array}{c}-0.206 * * \\
(0.091)\end{array}$ & $\begin{array}{c}0.006 \\
(0.061)\end{array}$ & $\begin{array}{l}-0.105 \\
(0.094)\end{array}$ \\
\hline Observations & 1,720 & 3,226 & 4,592 & 2,091 & 717 & 5,495 & 1,052 & 4,319 & 2,817 & 7,360 & 489 \\
\hline \# Firms & 1,057 & 2,100 & 3,241 & 1,396 & 395 & 2,931 & 765 & 2,337 & 1,864 & 6,150 & 226 \\
\hline Mean Dep Var & 0.062 & 0.071 & 0.011 & 0.038 & 0.007 & 0.024 & 0.004 & 0.013 & 0.014 & 0.003 & 0.004 \\
\hline
\end{tabular}

Notes: Standard errors are clustered by firm $(* * * \mathrm{p}<0.01, * * \mathrm{p}<0.05, * \mathrm{p}<0.1)$. Regressions include firm and industry-year fixed effects. 
Table 7: Further Test for Outsourcing

Dependent Variable: Log of Output (in constant prices) by Firm and Year

$\ln ($ scarcity)

ln Neighbor's Scarcity

Downstream Responsiveness ·

ln Neighbor's Scarcity

Year F.E.

Firm F.E.

Adjusted $\mathrm{R}^{2}$

$\mathrm{N}$
(1)

0.95

19,018

(2)

(3)

$\begin{array}{lll}-1.024 * * * & -0.465 * * & -1.037 \\ (0.332) & (0.190) & (0.331)\end{array}$

$2.647 * * *$

$2.199 * *$

$(0.988)$

$\begin{array}{rr}9.041 & * * * \\ (3.087) & (3.917)^{* *}\end{array}$

$\mathrm{Y} \quad \mathrm{Y}$

Y $\quad Y$

$\mathrm{Y} \quad \mathrm{Y}$

Y

0.95

0.95

19,018

19,018

Notes: Standard errors are clustered by firm $(* * * \mathrm{p}<0.01, * * \mathrm{p}<0.05, * \mathrm{p}<0.1)$. The variables Neighbor's Scarcity and Downstream Responsiveness are defined in the text. 
Table 8: Aggregate Production Costs of Change in Electricity Scarcity Since 1999

Panel A: Effects Evaluated at the Sample Mean of Each Independent Variable

\begin{tabular}{lrrrr} 
& $\begin{array}{r}\text { Marginal Cost } \\
\text { of Scarcity } \\
\text { (million Yuan } \\
(\sim \text { million US\$)) }\end{array}$ & F-Stat & $\begin{array}{r}\text { Cost of Scarcity, } \\
2000-2004 \\
\text { (billion Yuan } \\
(\sim \text { billion US\$) }\end{array}$ & $\begin{array}{r}\text { Percentage of } \\
\text { Aggregate Costs, } \\
2000-2004\end{array}$ \\
\hline Factor neutral effects & $-118(-\$ 15)$ & $2.95^{*}$ & $-360(-\$ 45)$ & $-2.3 \%$ \\
Factor biased effects & $510(\$ 64)$ & $176^{* * *}$ & $1552(\$ 194)$ & $10.1 \%$ \\
$\quad$ Capital & $0.6(\$ .08)$ & $1.8(\$ .23)$ & $0.0 \%$ \\
Labor & $-58(-\$ 7)$ & $-178(-\$ 22)$ & $-1.2 \%$ \\
Materials & $667(\$ 83)$ & $2032(\$ 254)$ & $13.2 \%$ \\
Electricity & $-89(-\$ 11)$ & $-270(-\$ 34)$ & $-1.8 \%$ \\
$\quad$ Non-electric energy & $-12(-\$ 1.5)$ & $-35(-\$ 4)$ & $-0.2 \%$ \\
Overall effects & $391(\$ 49)$ & $21.1^{* * *}$ & $1192(\$ 149)$ & $7.8 \%$ \\
\hline
\end{tabular}

Panel B: Mean of the Effects Calculated for Each Observation

\begin{tabular}{crrr} 
& $\begin{array}{r}\text { Marginal Cost } \\
\text { of Scarcity } \\
\text { (million Yuan } \\
(\sim \text { million US\$)) }\end{array}$ & $\begin{array}{r}\text { Cost of Scarcity, } \\
\text { 2000-2004 } \\
\text { (billion Yuan } \\
(\sim \text { billion US\$)) }\end{array}$ & $\begin{array}{r}\text { Percentage of } \\
\text { Aggregate Costs, } \\
2000-2004\end{array}$ \\
\hline Factor neutral effects & $-67(-\$ 8)$ & $-196(-\$ 25)$ & $-1.3 \%$ \\
Factor biased effects & $535(\$ 67)$ & $1513(\$ 189)$ & $9.8 \%$ \\
Capital & $3(\$ .4)$ & $5(\$ .6)$ & $0.0 \%$ \\
Labor & $-64(-\$ 8)$ & $-190(-\$ 24)$ & $-1.2 \%$ \\
Materials & $669(\$ 84)$ & $1918(\$ 240)$ & $12.5 \%$ \\
Electricity & $-79(-\$ 10)$ & $-222(-\$ 28)$ & $-1.4 \%$ \\
Non-electric energy & $7(\$ .9)$ & 0 & $0.0 \%$ \\
Overall effects & $468(\$ 59)$ & $1316(\$ 165)$ & $8.6 \%$ \\
\hline
\end{tabular}

Notes: The first column reports the marginal effect of scarcity based on the coefficient estimates of Table 4, Column 1. We report for both the factor neutral effects, including the effect on gross value of industrial output, as well as the factor bias effects for each factor. Fstatistics are reported for linear combinations of parameters in the top panel $(* * * p<0.01$, $* * \mathrm{p}<0.05, * \mathrm{p}<0.1$ ). The next column aggregates these total costs over 2000 to 2004 for the change in scarcity since 1999 . The last column divides these totals by the aggregate of all production costs in the sample from 2000 to 2004, which was 15,373 billion Yuan. 


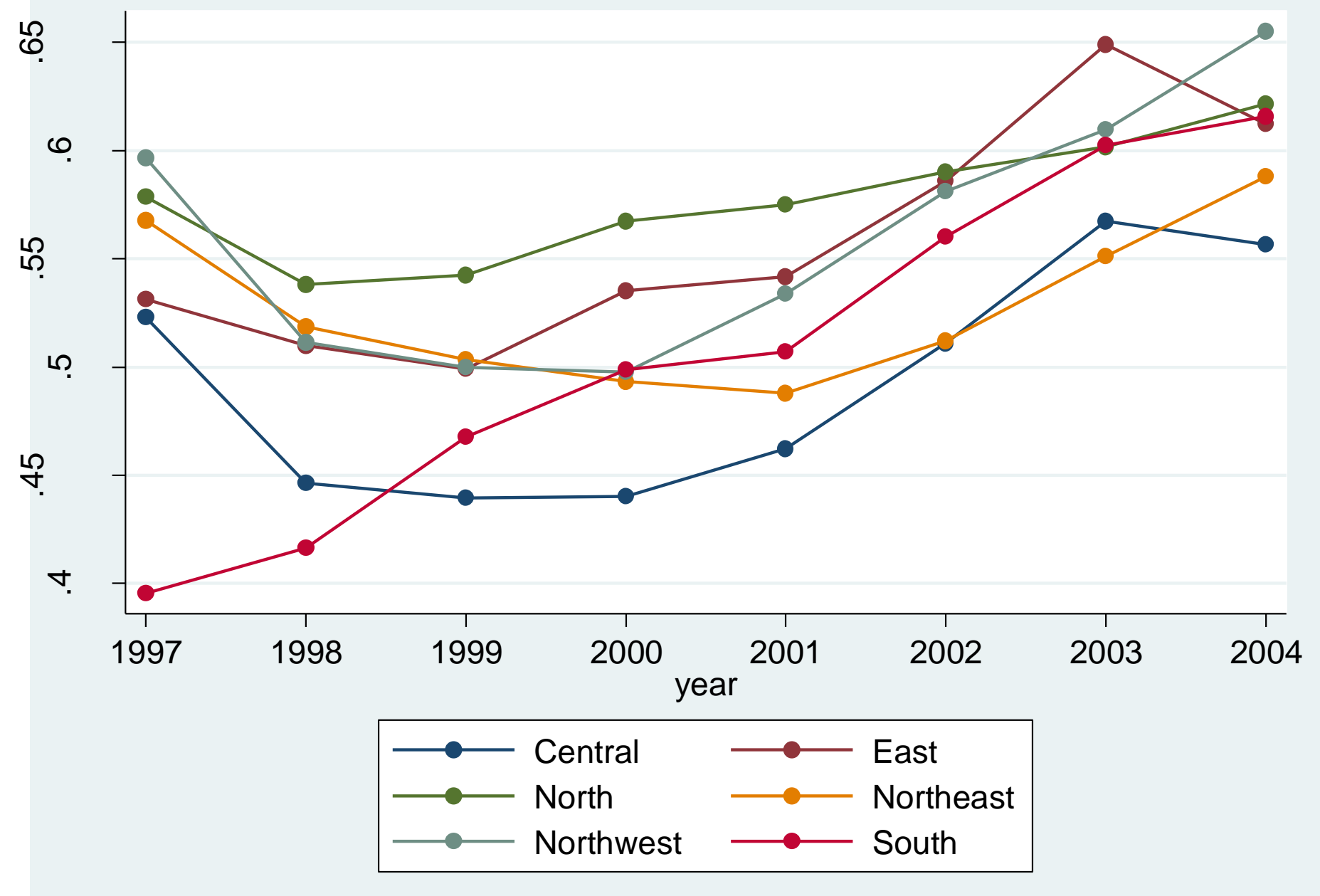

Figure 1: Annual Average Thermal Capacity Factor by Grid (mean 0.548, std.dev. 0.057) 